\title{
E-type Anaphora and Three Types of Kes-Construction in Korean
}

\author{
Min-Joo Kim \\ Texas Tech University \\ min-joo.kim@ttu.edu
}

\begin{abstract}
The overarching goal of this article is to account for why the Internally-Headed Relative Clause, the direct perception, and the factive constructions in Korean have an identical form involving the pronominal kes and the relativizer -un, despite the fact that one construction instantiates relativization and the other two instantiate complementation. I solve this puzzle by recasting Kim's (2007) analysis of Internally-Headed relatives in a Kratzerian situation semantic framework (e.g., Kratzer 1989, 1998, 2002). The central claim is that the three kes-constructions have an identical form because they all instantiate situation subordination that is facilitated by an E-type pronoun and a relativization strategy. The proposed analysis shows that E-type pronouns and relativizers can have more flexible semantics than widely assumed. It also sheds new light on the connection between modification and complementation across languages. Furthermore, it provides an argument for Kratzerian situation semantic theory in dealing with the interpretations of complex clauses.
\end{abstract}

Key words: E-type Anaphora, Internally-Headed Relative Clause construction, Direct Perception Construction, Factive Construction, Kratzerian situation semantics 


\section{Introduction}

Consider sentences (1), (2), and (3), which respectively exemplify what is called the Internally Headed Relative Clause (IHRC) construction, the direct perception construction, and the factive construction in Korean. ${ }^{1}$ These sentences show that the three constructions are stringidentical except for the embedding predicate. ${ }^{2}$ What is particularly noteworthy is that the object positions of all three constructions consist of clausal material followed by the grammatical categories -un and kes. ${ }^{3}$ The morpheme -un is invariably analyzed as the relativizer or

\footnotetext{
${ }^{1}$ In the IHRC construction, action verbs like 'catch', 'stop', and 'chase' usually occur as the embedding clause predicate. The embedding predicate of the perception construction is typically 'see', 'witness', 'hear', or 'feel'. Canonical examples of factive verbs are propositional attitude verbs like 'know', 'realize', 'notice', and 'forget'.

${ }^{2}$ It seems that languages that have the IHRC construction exhibit the same pattern: e.g., Quechua, as documented in Lefebvre and Muysken (1988). In Japanese, however, while the IHRC construction and the perception construction have an identical form in which no occurs in lieu of kes in Korean, the factive construction usually requires a different nominalizer, namely, koto (Yukinori Takubo, Shigeru Miyagawa, p. c.). According to Kuno (1973), the occurrence of koto replacing no has much to do with how abstract or propositional the content of the embedded clause is (p. 222). Even though Japanese seems to behave differently from Korean, the fact that it employs a different nominalizer for the factive construction from the IHRC and the perception constructions will prove to be supportive of the analysis to be given here, because we will see that the factive construction in Korean also behaves slightly differently from the other two kes-constructions.

${ }^{3}$ There are other constructions that have the same make-up as the three kes-constructions. For instance, some psychverbs can take the gapless clausal material + kes string as their complements, as shown in (i).
}

(i) Na-nun [[Swunhi-ka maumssi-ka chakha- $\varnothing]-n \quad$ kes-i maumeytu-n-ta.

I-TOP [[S.-NOM heart-NOM be.good-n.pst]-REL KES-NOM like-IMPRF-DECL

'I like the fact that Swunhi has a good heart.'

Or 'I like Swunhi because she has a good heart.' 
adnominalizer in the existing literature but the status of kes is less clear: it is usually analyzed as a pronominal in the IHRC construction (see Chung and Kim 2003, Kim 2004, Lee 2006) and as a nominalizer (e.g., Kim 1984, Jo 2003) or a complementizer in the other two constructions (e.g., Jhang 1994). In this article, I will treat kes as a pronominal in all three cases. To stay neutral in citing the existing literature, however, I will not gloss it until section 3, so it will be glossed as KES for the time being. 4

(1) The IHRC construction:

John-un [[totwuk-i tomangka-n]-un kes]-ul cap-ess-ta. J.-TOP [ [thief-NOM run.away-IMPRF]-REL KES]-ACC catch-PST-DECL 'John caught a/the thief while he (= the thief) was running away.'

In constructions like (i), however, the kes-string usually occurs bearing a Nominative case marker, while it occurs with Accusative case marking in the three kes-constructions introduced above. Furthermore, numerous instances of kes-constructions are hard to subsume under the rubric of the IHRC, the perception, or the factive construction (see Chae 2007). Hence, to keep matters simple, I do not discuss other kes-constructions like (i) until section 3.5, wherein we will see that the analysis I propose for the three kes- constructions can readily carry over to them.

${ }^{4}$ In this paper, Yale Romanization is adopted for transcribing the Korean data, and the following abbreviations are used:

ACC: accusative case; COMP: complementizer; CON: conditional; COP: copular verb; DAT: dative case; DECL: declarative sentence ending; FUT: future; GEN: genitive case; HON: honorific; IMPRF: imperfective aspect; IND: indicative mood marking; LOC: locative; MOOD: mood; NEG: negation; NOM: nominative case; PRON: pronoun; PST: past tense; PERF: perfect aspect; Q: question ending; REL: relative clause marker; TOP: topic. 
(2) The perception construction:

John-un [[totwuk-i tomangka-n]-un kes]-ul po-ess-ta.

J.-TOP [[thief-NOM run.away-IMPRF]-REL KES]-ACC See-PST-DECL

'John saw the event of the thief running away.'

(3) The factive construction: ${ }^{5}$

John-un [[totwuk-i tomangka-n]-un kes]-ul al-ess-ta.

J.-TOP [[thief-NOM run.away-IMPRF]-REL KES]-ACC know-PST-DECL

'John knew (the fact) that the thief was running away.'

The fact that the IHRC, the perception, and the factive constructions in Korean share the surface form is intriguing because they exhibit rather clear interpretive differences. For instance, while the embedded clause plus kes string (henceforth 'kes string') seems to serve as the object of the embedding predicate in the perception and the factive constructions, in the IHRC construction, it seems to be supplying both the object of the embedding predicate and a modifier thereof, as indicated by the English translation of (1). In addition, the string is interpreted as denoting an eventuality in the perception construction and a fact in the factive construction but an individual in the IHRC construction-e.g., the thief in (1).

\footnotetext{
${ }^{5}$ In Korean, sentences containing non-factive attitude verbs, such as 'think' or 'say', bear a different form involving ko-complementation, as shown in (i).

(i) John-un [totwuk-i tomangka-n-ta]-ko malhay-/saynkakhay-ess-ta.

J.-TOP [thief-NOM run.away-IMPRF-IND]-COMP say/think-PST-DECL

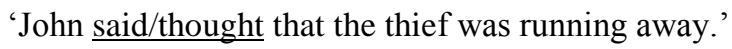


These differences between the three constructions raise at least three questions:

(i) Why do they surface bearing the same form, despite the interpretive differences?

(ii) How else do they differ from each other?

(iii) Do they have any similarities other than the seemingly identical surface form?

To my knowledge, these questions have not been addressed in the literature. Currently, the three constructions are treated separately on the basis of the fact that the IHRC construction instantiates relativization whereas the perception and the factive constructions instantiate complementation (see, among others, Kim 1984, Jhang 1994, Chung 1999, Chung and Kim 2003). Answering the above questions properly will therefore contribute to the existing body of knowledge, and that is what this paper hopes to accomplish.

I show that the three constructions display several subtle semantic differences at the microlevel but are similar at the macro-level and thus can receive an essentially uniform treatment. ${ }^{6}$ At its core, this globally uniform treatment of the three constructions is an extension of Kim's (2007) E-type pronoun analysis of the IHRC construction to the perception and the factive constructions. Yet, departing from the event-based framework adopted in that work, I will adopt Kratzerian situation semantics here, more precisely what is expounded in $\operatorname{Kratzer}(1989,1998)$. In addition, Kratzer's (2002) treatment of knowledge ascriptions will be adopted in dealing with the factive construction. The central claim will be that, in all three constructions, - un invariably relates two sets of situations in the denotations of the embedded and the embedding clauses, whether they feel like events or worlds, and kes represents an E-type pronoun whose denotation

\footnotetext{
${ }^{6}$ By this, I do not mean to say that they are identical constructions, though.
} 
relates a situation to a salient entity in it, be it a minimal or a maximal situation. Under the analysis to be developed here, such a flexible semantic treatment of -un and kes is possible because, in a Kratzerian situation semantics framework, eventualities, states of affairs, and worlds can be simply different types of situations that stand in a part-whole relation to each other and, just like individuals, situations and worldly facts can be uniformly treated as particulars or concrete objects. $^{7}$

The remainder of this paper proceeds as follows: section 2 takes a closer look at the three kes-constructions and shows how exactly they are similar and dissimilar to each other. Section 3 develops a situation semantical analysis of the three constructions. At the end of this section, I also discuss how the semantic analysis developed here accounts for the various properties of the three constructions identified earlier. I also show how it can extend to other kes-constructions that are not discussed in this paper for the reasons given in footnote 3 . Finally, section 4 closes the paper with a summary and conclusion.

2 How exactly are the three kes-constructions similar or dissimilar to each other?

In this section, I compare the three kes-constructions with respect to five semantic properties: (i) referential transparency, (ii) indicative mood-marking, (iii) predicate restriction, (iv) presuppositionality, and (v) the interpretive behavior of kes. As mentioned above, a widelyheld view in the literature is that the IHRC construction forms a separate class from both the direct perception construction and the factive construction. I show that although it is certainly indisputable that the former instantiates relativization and the latter two instantiate

\footnotetext{
${ }^{7}$ In this paper, I use the term 'entities' to refer to both 'individuals' and non-individual-like particulars, such as 'events' and 'situations'; the term 'individuals' will be mostly kept for human and animate things.
} 
complementation, there is reason to rethink the prevailing classification. In order to make such points, I first present some of the characteristic properties of the factive construction and then show how they are shared or not shared by the other two kes-constructions.

\subsection{Referential transparency of the complement position}

A well-known fact in semantics literature is that factive verbs like 'know' and direct perception verbs like 'see' differ from each other in terms of the referential transparency of their complement positions. This can be seen by utilizing what is called the substitution test for intensionality. To illustrate, consider (4) and (5). These paradigms show that, while knowledge ascriptions do not pass the substitution test, direct perceptual reports do, suggesting that the former are referentially opaque while the latter are referentially transparent. (For further discussion about English cases, see, among others, Barwise 1981, Higginbotham 1983, Berg 1988).

(4)a. Lois Lane knows that Clark Kent is a reporter.

b. Clark Kent is Superman.

$=/=>$ c. Lois Lane knows that Superman is a reporter. (INVALID)

(5)a. Lois Lane saw Clark Kent leave the office.

b. Clark Kent is Superman

$\rightarrow$ c. Lois Lane saw Superman leave the office. (VALID) 
Notice now that the same kind of contrast obtains between the perception and the factive constructions in Korean, as exemplified by (6) and (7).

(6) The factive construction:

a. John-un totwuk-i tomangka-n-un kes-ul al-ess-ta.

J.-TOP thief-NOM run.away-IMPRF-REL KES-ACC know-PST-DECL

'John knew that the thief was running away.'

b. $\mathrm{Ku}$ totwuk-un Chinho-i-ess-ta.

The thief-TOP Chinho-COP-PST-DECL

'That thief was Chinho.'

=/=> c. John-un Chinho-ka tomangka-n-un kes-ul al-ess-ta.

J.-TOP C.-NOM run.away-IMPRF-REL KES-ACC know-PST-DECL

'John knew that Chinho was running away.' (INVALID)

(7) The perception construction:

a. John-un totwuk-i tomangka-n-un kes-ul po-ess-ta.

J.-TOP thief-NOM run.away-IMPRF-REL KES-ACC see-PST-DECL

'John saw the event of the thief running away.'

b. $\mathrm{Ku}$ totwuk-un Chinho-i-ess-ta.

The thief-TOP Chinho-COP-PST-DECL

'That thief was Chinho.'

$\rightarrow$ c. John-un Chinho-ka tomangka-n-un kes-ul po-ess-ta.

J.-TOP C.-NOM run.away-IMPRF-REL KES-ACC see-PST-DECL 
'John saw the event of Chinho running away.' (VALID)

The fact that the factive and the perception constructions in Korean behave differently with respect to referential transparency does not really surprise us, because semantic properties like referential transparency (or opacity) are likely to hold universally. What may come as a slight surprise is that the IHRC construction patterns exactly like the perception construction in this regard. To see this, compare (7) and (8).

(8) The IHRC construction:

a. John-un totwuk-i tomangka-n-un kes-ul cap-ess-ta.

J.-TOP thief-NOM run.away-IMPRF-REL KES-ACC catch-PST-DECL

'John caught the thief while he was running away.'

b. $\mathrm{Ku}$ totwuk-un Chinho-i-ess-ta.

The thief-TOP Chinho-COP-PST-DECL

'That thief was Chinho.'

$\rightarrow$ c. John-un Chinho-ka tomangka-n-un kes-ul cap-ess-ta.

J.-TOP C.-NOM run.away-IMPRF-REL KES-ACC catch-PST-DECL

'John caught Chinho while he was running away.' (VALID)

This leads us to conclude that when it comes to referential transparency or opacity of the complement position, there is more affinity between the IHRC and the perception constructions than between the perception and the factive constructions. 
2.2 Indicative mood marking inside the embedding clause

Another semantic property I would like to employ to compare the three kes-constructions is the possibility or impossibility of indicative mood marking on the embedded clause's predicate.

In Korean, the morpheme - $t a$ occurs on the predicate of a clause, indicating that it is a declarative sentence. This is illustrated by all the Korean sentences presented thus far, for they all end with -ta and are making some sort of assertion. Given this, -ta can be analyzed as an indicative mood marker, even though it is glossed here as a declarative sentence ending. Thus, it is expected to occur inside the embedded clause that has an assertoric force, as illustrated in (9).

$\begin{array}{llll}\text { (9) John-un } & \text { [totwuk-i } & \text { tomangka-n-ta]-ko } & \text { malhay-ss-ta. } \\ \text { J.-TOP } & \text { [thief-NOM } & \text { run.away-IMPRF-IND]-COMP } & \text { say-PST-DECL }\end{array}$

'John said that the thief was running away.'

When we turn to the three kes-constructions, we see that, while $t a$-marking is allowed on the embedded predicate of the factive construction, it is disallowed on the embedded predicates of the perception and IHRC constructions, as exemplified in (10), (11), and (12).

(10) The factive construction:

\begin{tabular}{|c|c|c|c|c|}
\hline John-un & [totwuk-i & tomangka-n-ta]-nun & kes-ul & alassta/kattalassta \\
\hline J.-TOP & [thief-NOM & run.away-IMPRF-IND]-REL & KES-ACC & knew/realized \\
\hline
\end{tabular}


The perception construction:

*John-un [totwuk-i tomangka-n-ta]-nun kes-ul poassta/tulessta.

J.-TOP [thief-NOM run.away-IMPRF-IND]-REL KES-ACC saw/heard

Intended: 'John saw/heard the thief running away.'

(12) The IHRC construction:

*John-un [totwuk-i tomangka-n-ta]-nun kes-ul capassta/makassta.

J.-TOP [thief-NOM run.away-IMPRF-IND]-REL KES-ACC caught/stopped

Intended: 'John caught/stopped the thief running away.'

Since $t a$-marking is considered a hallmark of an indicative sentence, we can take the contrast between the above three sentences to suggest that only the embedded clause of the factive construction has an assertoric force of its own. Alternatively, we can take it to suggest that only the factive complement can denote a proposition; the complements of the IHRC and the perception denote something smaller, such as a set of eventualities or situations. Whatever may turn out to be the right conclusion, what is clear at this point is that the IHRC and the perception constructions pattern together with regard to the occurrence of indicative mood making inside the embedded clause.

\subsection{Predicate restriction on the embedded clause}

Another criterion with which to compare the three kes-constructions is a predicate restriction on the embedded clause, more specifically, whether the embedded clause can have both individual-level (I-level) predicates and stage-level (S-level) predicates in the sense of Carlson 
(1977), which respectively describe semi-permanent properties of individuals and spatiotemporally bound stages of individuals.

To begin with the factive construction, the embedded clause can have either an I-level predicate or an S-level predicate, as exemplified by (13). ${ }^{8}$

(13) a. John-un [[Mary-ka changnankkwuleki-i- $\varnothing]$-un kes]-ul alassta/kattalassta

J.-top [[M.-nom goofy.person-COP-N.PST]-REL KES $]$-ACC knew/realized 'John knew/realized that Mary is/was a goofy person.'

b. John-un [[Mary-ka changnanchi-n]-un kes]-ul alassta/kattalassta.

J.-top [[M.-nom goof.around-N.PST]-REL KES $]$-ACC $\quad$ knew/realized

'John knew/realized that Mary is/was goofing around.'

As for the other two kes-constructions, several authors have observed that the embedded clause of the IHRC construction cannot contain an I-level predicate (e.g., Y.-B. Kim 2002, Chung and Kim 2003, C.-M. Lee 2001, M. Lee 2003). ${ }^{9}$ What is important to note here is that the same restriction holds for the perception construction as well. To see this, consider (14) and (15) in comparison with (13).

\footnotetext{
${ }^{8}$ In Korean, the non-past marker for adjectives and adjective nominals is the zero morpheme or $\varnothing$, as illustrated in (13a), whereas its counterpart for verbs is $-n$, as illustrated in (13b).

${ }^{9}$ This is also true for the Japanese IHRC construction, as observed by Matsuda (2002).
} 
(14) a. *John-un [[Mary-ka changnankkwuleki-i- $\varnothing]$-un kes]-ul capassta/makassta.

J.-top [[M.-nom goofy.person-COP-N.PST]-REL KES]-ACC caught/stopped

Intended: 'John caught/stopped Mary, who is a goofy person.'

b. John-un [Mary-ka changnanchi-n]-un kes-ul capassta/makassta.

J.-top [M.-nom goof.around-N.PST]-REL KES]-ACC caught/stopped

'John caught/stopped Mary when she was goofing around.'

(15) a. *John-un [[Mary-ka changnankkwuleki-i- $\varnothing]$-un kes]-ul poassta/tulessta.

J.-top [[M.-nom goofy.person-COP-N.PST]-REL KES]-ACC saw/heard

Intended: 'John saw/heard Mary being a goofy person.'

b. John-un [[Mary-ka changnanchi-n]-un kes]-ul poassta/tulessta

J.-top [[M.-nom goof.around-N.PST]-REL KES]-ACC saw/heard

'John saw/heard Mary goofing around.'

When we look at the ungrammatical sentences in (14) and (15), the ungrammaticality of (15a) is expected because one cannot directly perceive someone's semi-permanent property such as being a goofy person. The ungrammaticality of (14a), by contrast, is not entirely expected because it should be possible to apply an action to an individual who has a certain semipermanent property.

Undoubtedly, this puzzle merits attention and an account. Yet it has to wait till section 3.4. What matters for now is that there is a definite contrast between the factive construction and the perception and the IHRC construction with respect to the predicate restriction on the embedded clause. This fact again leads us to group the latter two together, contra the prevailing view. 


\subsection{Presuppositionality of the complement position}

Let us turn now to examining the three constructions in terms of the existential presuppositionality requirement on the complement position. This discussion is relevant for us because presuppositionality is a cross-linguistically well-established property of the factive construction, due largely to Kiparsky \& Kiparsky (1970) and much subsequent work.

As exemplified in (16)-(18), the semantics of the complement position of the factive kesconstruction is such that the existential presupposition imposed on it survives even in negative, interrogative, and counterfactual contexts, which are considered presupposition holes in the sense of Karttunen (1973). All these sentences entail that some (salient) thief ran way in the actual world. This is evidenced by the fact that they cannot be followed by an utterance like Kuluntey, totwuk-un tomangkaci anhassta 'But, the thief did not run away', as shown in (16). (For space reasons, I do not repeat the same tests in (17) and (18).)

The factive construction:

\begin{tabular}{|c|c|c|}
\hline John-un & totwuk-i & tomangka-n-un \\
\hline J.-TOP & thief-NOM & run.away-IMPRF-REL KES-ACC know-NEG \\
\hline \multicolumn{3}{|c|}{ motha-ess-ta. } \\
\hline \multicolumn{3}{|c|}{ NEG-PST-DECL } \\
\hline \multicolumn{3}{|c|}{ 'John did not know that a/the thief was running away.' } \\
\hline \#Kuluntey, & totwuk-un & tomangkaci \\
\hline But, & thief-top & run.away \\
\hline
\end{tabular}

'But, the thief did not run away' 


$\begin{array}{lllll}\text { John-un } & \text { totwuk-i } & \text { tomangka-n-un } & \text { kes-ul } & \text { al-ess-ni? } \\ \text { J.-TOP } & \text { thief-NOM } & \text { run.away-IMPRF-REL } & \text { KES-ACC } & \text { know-PST-Q }\end{array}$

'Did John know that a/the thief was running away?'

(18)

$\begin{array}{lrlll}\text { Manil } & \mathrm{John}_{\mathrm{i}} \mathrm{-i} & \mathrm{ku} \text { cenhwa-lul } & \text { pat-ess-ta-meyn, } \\ \text { if } & \mathrm{J} . \mathrm{NOM} & \text { the phone.call-ACC } & \text { receive-PST-IND-COND, } \\ \text { pro }_{\mathrm{i}} & \text { totwuk-i } & \text { tomangka-n-un } & \text { kes-ul } & \text { al-ess-ulthen-tey. } \\ & \text { thief-NOM } & \text { run.away-IMPRF-REL } & \text { KES-ACC } & \text { know-PST-MOOD-DECL }\end{array}$

'If John had received the phone call, he would have known that a/the thief was running away.'

Several authors have noted that the perceptual kes-construction is also presuppositional with respect to the complement position (Chung and Kim 2003, Chung 1999). This can be confirmed by the semantic properties of sentences that occur in negative, interrogative, and counterfactual contexts such as the following: just as in (16)-(18), these sentences also presuppose the existence of the event of some (salient) thief running away, as evidenced by the infelicitous continuation in (19). 
The perception construction:

(19)

John-un totwuk-i tomangka-n-un kes-ul po-ci

J.-TOP thief-NOM run.away-IMPRF-REL KES-ACC see-NEG

mos-ha-ess-ta.

NEG-DO-PST-DECL

'John did not see the event of the thief running away.'

\#Kuluntey, totwuk-un tomangkaci anhassta.

But, thief-top run.away did.not

'But, the thief did not run away'

(20) John-un totwuk-i tomangka-n-un kes-ul po-ess-ni?

J.-TOP thief-NOM run.away-IMPRF-REL KES-ACC see-PST-Q

'Did John see the event of the thief running away?'

(21) Manil John $\mathrm{i}_{\mathrm{i}} \mathrm{i}$ ku ttay cip-ey iss-ess-ta-meyn,

if J.-NOM that time home-LOC exist-PST-IND-COND,

pro $_{\mathrm{i}}$ totwuk-i tomangka-n-un kes-ul po-ess-ulthen-tey.

thief-NOM run.away-IMPRF-REL KES-ACC See-PST-MOOD-DECL

'If John had been home at that time, he would have seen the event of the thief running away.'

Interestingly, however, the presuppositionality exhibited by the complement of a direct perceptual verb is not factive, unlike the case with the factive construction. For instance, when 
the complement of a direct perceptual verb occurs under an intensional predicate like 'want' while bearing imperfective aspect, its presupposition can be canceled, even if the matrix clause is set in an episodic context. To see this, consider (22) against the following backdrop: a year ago Mary had a leg injury. Recently, she recovered from it, so she decided to participate in today's marathon. John was looking very much forward to seeing her run for the first time in a year. But, unbeknownst to John, at the last minute, she decides not to participate in the race for fear of not completing it.

\begin{tabular}{|c|c|c|c|c|c|}
\hline John-un & Mary-ka & talli-n-un & kes-ul & po-ko & ship-ess-ta. \\
\hline J.-TOP & thief-NOM & run-IMPRF-REL & KES-ACC & po-COMP & WANT-PST-DECL \\
\hline \multicolumn{6}{|c|}{ 'John wanted to see Mary run.' } \\
\hline Haciman, & kunye-nun & makphan-ey & $\underline{\text { talliki-lul }}$ & phokihays & \\
\hline But, & she-TOP & last.minute-LOC & \multicolumn{3}{|c|}{ running-ACC gave-up } \\
\hline
\end{tabular}

Obviously, (22) is judged felicitous even though the second sentence cancels the presupposition that John had about the event described by the embedded clause of the first sentence. The felicity of this discourse clearly shows that, under certain circumstances, such as under the workings of intensionality and imperfectivity as in (22), the complement of a direct perception verb may not denote a fact. This leads us to conclude that the presuppositionality that is at work in the perception construction is slightly different from what is at work in the factive construction. Now the question is how to make sense of it. 
Below I elaborate further on this issue and offer a formal analysis in section 3. Before we get there, though, I would like to point out that the IHRC construction behaves like the perception construction in terms of presuppositionality, a property that has gone unnoticed in the literature, as far as I am aware. To see this, compare first (19)-(21) and (23)-(25). Just like the former, the latter presuppose the existence of the event of some thief running away, as the pragmatic anomaly of (23) shows.

The IHRC construction:

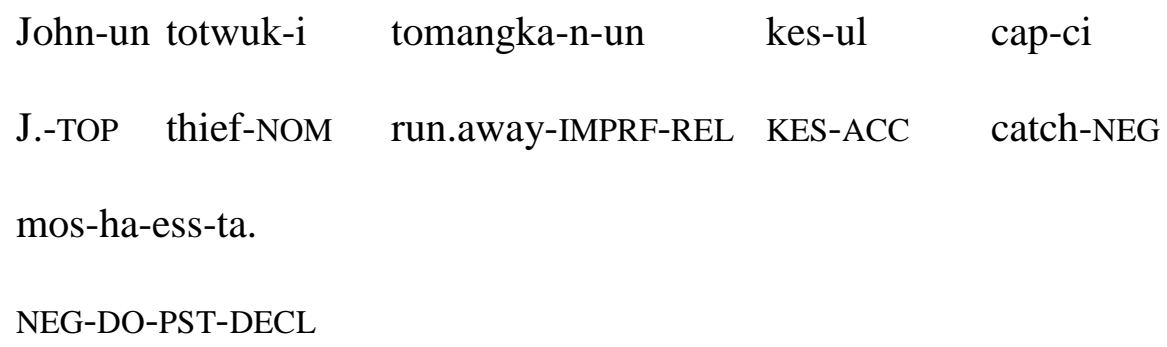

'But, the thief did not run away'

(24) John-un totwuk-i tomangka-n-un kes-ul cap-ess-ni?

J.-NOM thief-NOM run.away-IMPRF-REL KES-ACC catch-PST-Q

'Did John catch the thief while he was running away?' 


$$
\begin{aligned}
& \text { Manil John } \mathrm{i}_{\mathrm{i}} \mathrm{i} \quad \mathrm{ku} \text { ttay cip-ey iss-ess-ta-meyn, } \\
& \text { if J.-NOM that time home-LOC exist-PST-IND-COND, } \\
& \text { pro }_{\mathrm{i}} \text { totwuk-i tomangka-n-un kes-ul cap-ess-ulthen-tey. } \\
& \text { thief-NOM run.away-IMPRF-REL KES-ACC catch-PST-MOOD-DECL }
\end{aligned}
$$

'If John had been home at that time, he would have caught the thief while he was running away.'

Notice now that when we look at cases in which an IHRC occurs under an intensional predicate with imperfective aspect inside, we obtain the same kind of non-factivity as in (22). The following is an illustrative case: even though the second sentence cancels the presupposition of the first sentence, the discourse goes through fine, without incurring any pragmatic anomaly or self-contradiction.

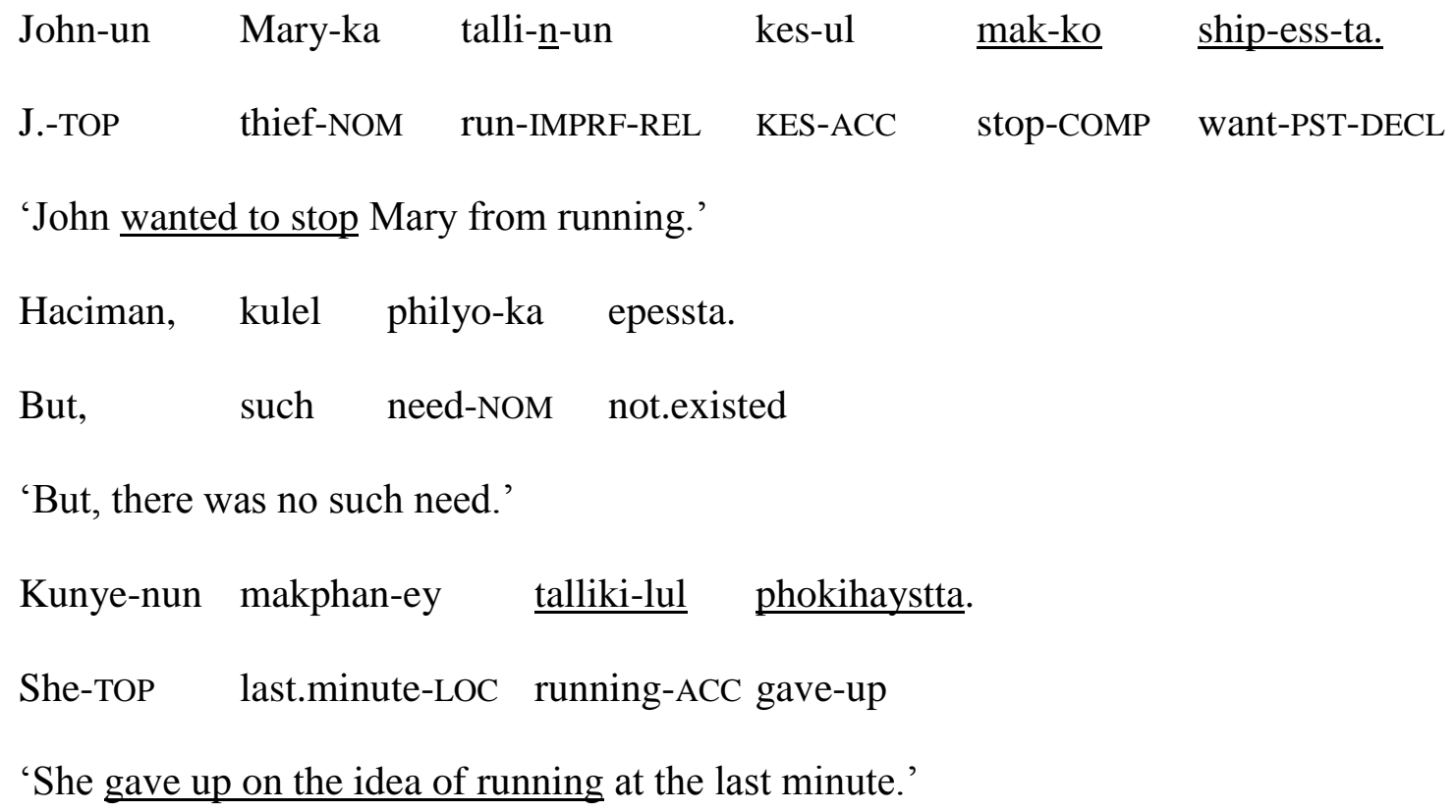


Given this state of affairs, a descriptive generalization I would like to offer is that all the three kes-constructions are presuppositional with respect to the complement position but the precise nature of this property is different from one case to another. The presuppositionality triggered in the factive construction is true factivity (and hence the name of the construction) and what is triggered in the other two constructions is mere existential presuppositionality or potential factivity: the latter surfaces as potential factivity when the embedded clause is under an intensional operator and it contains imperfective aspect, as shown in (22) and (26). ${ }^{10}$

${ }^{10}$ An anonymous reviewer has raised an issue with this generalization. He/she observes that, unlike the complements of direct perceptual verbs, IHRCs invariably exhibit factivity, even in intensional contexts.

At first glance, this observation appears correct, since the sentence below does seem to presuppose that Mary actually made bread although, in the first utterance, an IHRC is embedded under an intensional verb 'want', in contrast to the case in (22).

(i)

\begin{tabular}{|c|c|c|c|c|}
\hline John-un & Mary-ka & ppang-ul & mantu- $\varnothing$-un & kes-ul \\
\hline J.-TOP & M.-NOM & bread-ACC & make-PRF-REL & KES-ACC \\
\hline \multicolumn{5}{|l|}{ ship-ess-ta. } \\
\hline \multicolumn{5}{|c|}{ want-PAST-DECL } \\
\hline \multicolumn{5}{|c|}{ 'Mary made bread and John wanted to eat it (= the bread she made).' } \\
\hline \#Kulentay, & sashilun & Mary-nun & mantul-ci & anhassta. \\
\hline But, & in.fact & M.-TOP & bread-ACC & did.not \\
\hline
\end{tabular}

I would like to point out, however, that the sentences the anonymous reviewer brings up for comparison do not actually form minimal pairs. The IHRC sentences he/she provides all have perfect aspect in the embedded clause, as is the case in (i) in this footnote, whereas all the perception sentence have imperfective aspect, such as (22) in the text. So they are not exactly comparable to each other. 
This finding seems to be subject to two different kinds of interpretation. On the one hand, it seems to reinforce our findings in the preceding subsections and suggest that there are some fundamental differences between the IHRC/perception construction and the factive construction. On the other hand, it seems to suggest that, from a broader perspective, the three constructions are not so different from each other: they all exhibit some sort of presuppositionality. What differs between them is that, in the factive construction, what is presupposed holds in the actual

When we keep the aspect of the embedded clause identical, we obtain an identical pattern between the two constructions. For instance, in (ii) below, which exemplifies the perception construction, the embedded clause of the first sentence has perfect aspect, just like in (i), and continuing the discourse with the second sentence is just as anomalous as in (i).

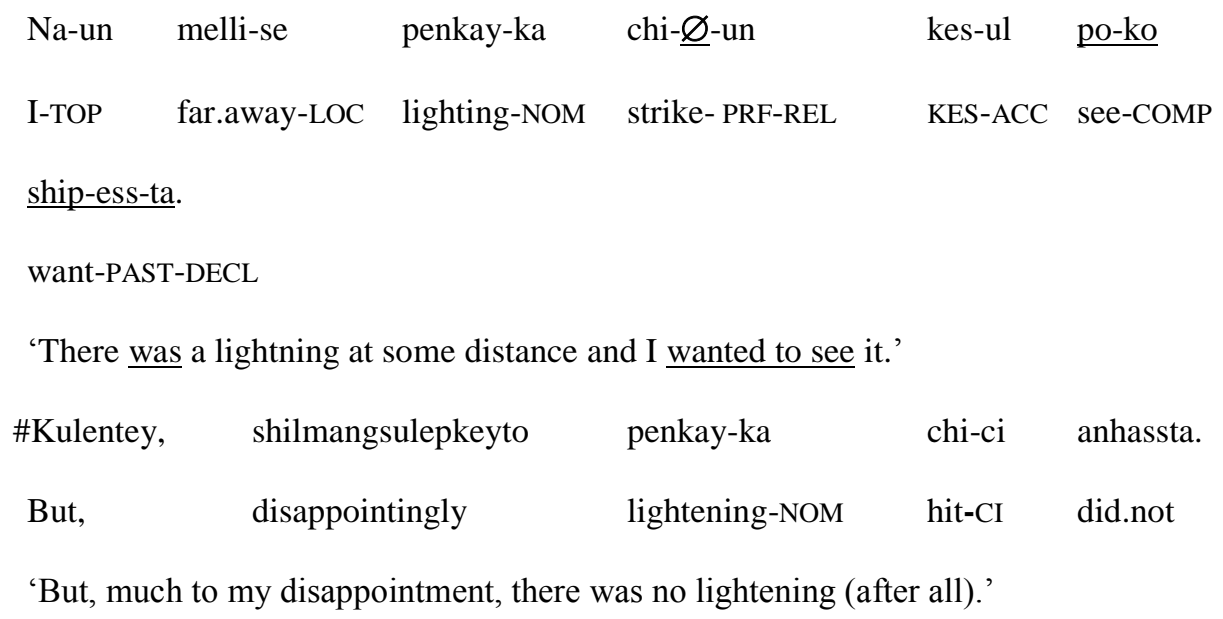

In my view, the parallels between (i) and (ii) and those between (22) and (26) unequivocally show that, in both the perception and IHRC constructions, presuppositionality manifests itself as true factivity when the tense/aspect of the embedded clause is perfect, and as potential factivity when the aspect is imperfective. I therefore conclude that there is actually no fundamental difference between the two constructions with respect to presuppositionality, contrary to the reviewer's claim; the apparent difference he/she detects simply reflects the different tense/aspect marking in the embedded clause that happens to be uncontrolled for. 
world whereas, in the IHRC and the perception constructions, it holds in some world, which can sometimes be the actual world. This generalization seems to adequately capture our intuitions that the presuppositionality triggered by the IHRC and the perception construction reflects the belief of some relevant individual, which is not necessarily the speaker or the matrix subject, whereas the presuppositionality triggered by the factive construction does reflect the speaker's belief which has been verified and thus has been established as a fact, provided that the speaker is not mistaken about things in the actual world. This second interpretation is what I will adopt and capitalize on in this paper, as we will see in section 3. For now, though, let us take a look at the last property that pertains to the three kes-constructions.

\subsection{The pronominal interpretation of kes}

We have just seen that existential presuppositionality can potentially bring the IHRC and the perception constructions closer to the factive construction, in addition to their identical surface form. We will observe now that there is yet another property that brings them closer to each other: it is the way in which kes is interpreted. To illustrate, consider (27), which instantiates the factive construction, repeated from (4).

$$
\begin{aligned}
& \begin{array}{llll}
\text { John-un }[\text { totwuk-i } & \text { tomangka-n]-un } & \text { kes]-ul } & \text { alassta. } \\
\text { J.-TOP [[thief-NOM } & \text { run.away-IMPRF]-REL } & \text { KES }]-A C C & \text { knew }
\end{array} \\
& \text { 'The thief was running away and John knew it (= the fact).' }
\end{aligned}
$$

According to native speakers' intuitions, the object position of this sentence is interpreted as referring to the fact that instantiates the proposition described by the embedded clause. The 
importance of this interpretation is two-fold: first, it shows that kes's meaning is definite. The other is that this grammatical category behaves like a pronoun in that interpreting it involves recovering a salient property that restricts it. This is evidenced by the fact that kes can actually be replaced by a lexical noun that literally means 'fact', namely, sashil, as shown in (28) without causing any semantic harm to the original sentence. ${ }^{11,12}$

$$
\begin{array}{lllll}
\text { John-un } & {[[\text { totwuk-i }} & \text { tomangka-n(-ta)]-un } & \text { sashil }]- \text {-ul } & \text { alassta. } \\
\text { J.-TOP } & {[[\text { thief-NOM }} & \text { run.away-IMPRF(-IND)]-REL } & \text { fact }]-A C C & \text { knew }
\end{array}
$$

'A/the thief was running away and John knew the fact.'

Notice that the properties displayed by kes in the factive construction are shared by those in the perception construction. In the latter, the object position is interpreted as referring to some unique perceptual aspect of the eventuality described by the embedded clause such as 'scene' or 'sound'. That is, it is construed as referring to the scene or sound of the event described by the embedded clause. Evidence for this comes from the fact that the kes that occurs in (29) can be replaced by a lexical noun such as soli 'sound' as exemplified in (30).

$$
\begin{array}{lllll}
\text { John-un } & {[\text { totwuk-i }} & \text { tomangka-n]-un } & \text { kes]-ul } & \text { tulessta. } \\
\text { J.-TOP } & \text { [[thief-NOM } & \text { run.away-IMPRF]-REL } & \text { KES]-ACC } & \text { heard } \\
\text { 'The thief was running away and John heard it (= the sound).' } &
\end{array}
$$

\footnotetext{
${ }^{11}$ According to Shigeru Miyagawa (p.c.), the same is true of Japanese IHRCs as well.

${ }^{12}$ For reasons unknown to me at this point, this lexical substitution is better with the indicative mood marker -ta overtly realized in the embedded clause.
} 
John-un [[totwuk-i tomangka-n]-un soli]-lul tulessta.

J.-TOP [[thief-NOM run.away-IMPRF]-REL sound]-ACC heard

'A/the thief was running away and John heard the sound.'

Now, what about the IHRC construction? In Kim (2007), I have claimed that the IHRC construction instantiates E-type anaphora: the IHRC+kes string denotes a unique or maximal individual that stands in a salient relation to the eventuality described by the embedded clause. I have further argued that this relation is a thematic relation such as Agent and Theme. Support for this idea comes from the observation that the kes that occurs in sentence (31) can be replaced by a lexical expression, as shown in (32).

$$
\begin{array}{lllll}
\text { John-un } & \begin{array}{l}
\text { [ totwuk-i } \\
\text { tomangka-n]-un }
\end{array} & \text { kes]-ul } & \text { capassta. } \\
\text { J.-TOP } \quad[[\text { thief-NOM } & \text { run.away-IMPRF]-REL } & \text { KES]-ACC } & \text { caught } \\
\text { 'The thief was running away and John caught him (= the thief).' }
\end{array}
$$

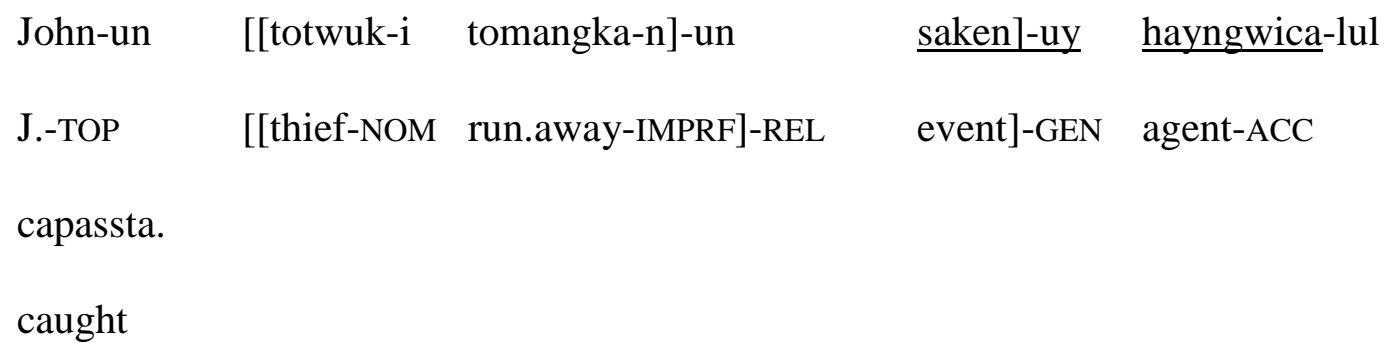

'A/the thief was running away and John caught the agent of the event, i.e., the thief.' 
These facts, taken together, show that, in all three constructions, kes behaves like some sort of pronominal. We can therefore add yet another property to the list of commonalities we have compiled for them.

\subsection{Summary}

In this subsection, we have seen that the complement positions of the IHRC construction and the perception construction pattern together with respect to referential transparency, indicative mood-marking, and predicate restriction but this parallel is not shared by the complement position of the factive construction. ${ }^{13} \mathrm{We}$ have also seen, however, that the three constructions

\footnotetext{
${ }^{13}$ It is also widely held that there is a temporal restriction on the IHRC construction and the perception construction whereas it is not imposed on the factive construction: the embedded clause's event time cannot precede that of the embedding clause's event time (e.g., Kim 2002, Lee 2004, Matsuda 2002, Kim 2004). Further probing reveals, however, that this restriction in fact admits numerous exceptions, as shown by the following examples ((ii) is due to Hee-Rak Chae, p.c.):
}

(i) The IHRC construction:

$\begin{array}{lllll}\text { Yenghee-nun } & {[[\text { sakwa-ka }} & \text { taum-cwu-ey } & \text { swuchwul-toy]-1 } & \text { kes-ul } \\ \text { Y.-TOP } & \text { [[apple-NOM } & \text { next-week-LOC } & \text { export-PASS]-REL.FUT } & \text { KES-ACC } \\ \text { onul } & \text { mili } & \text { phocangha-ess-ta. } & & \\ \text { today } & \text { in.advance } & \text { pack-PST-DECL } & & \end{array}$

'The apples are going to be exported next week but Yenghee packed them today in advance.' 
behave more alike in terms of the existential presuppositionality requirement on the complement position and the pronominal-like interpretive behavior of kes. A proper analysis of the three constructions should therefore be able to derive their fine-grained differences while also capturing their commonalities. Developing such an analysis will be the task of the next section, to which we now turn.

\section{An E-type pronoun analysis of the three kes-constructions}

The goal of this section is to propose a locally individualized but globally uniform analysis of the three kes-constructions. I will do this by revising an E-type pronoun analysis of the IHRC construction I have offered in Kim (2007) and extending it to the other two kes-constructions. Therefore, I begin this section with a brief overview of Kim (2007).

\subsection{Kim's (2007) E-type pronoun analysis of the IHRC construction}

In Kim (2007), I have proposed that, in the IHRC construction in Korean, the relative clause occurs as the complement to an N-level pronoun kes, which is in turn complement to a phonologically null [+ definite] feature. This is schematically depicted in (33) for sentence (1).

(ii) The perception construction:

Context: John is watching a TV drama that has a character named Mary appearing in it.

John-un [[Mary-ka taumcwu-ey cwuk]-ul kes]-ul mili po-keytoy-ess-ta.

J.-TOP [[M -NOM next.week-LOC die]-REL.FUT kes]-ACC in.advance see-happen.to-PST-DECL

'Mary is going to die next week and John happened to see it (= the event) in advance (because the broadcasting company showed it as a preview).'

The above data show that a temporal restriction is not a reliable enough diagnostic to tease apart the IHRC and the perception constructions from the factive construction. Thus I do not include it in the discussion here. 
(Note that, from this point forward, kes is glossed as PRON, shorthand for pronominal, rather than as KES.)

$\begin{array}{lllll}\text { John-un } & {[[\text { totwuk-i }} & \text { tomangka-n]-un } & \text { kes }]- \text { ul } & \text { cap-ess-ta. } \\ \text { J.-TOP } & {[[\text { thief-NOM }} & \text { run.away-IMPRF }]-R E L & \text { PRON }]-A C C & \text { catch-PST-DECL }\end{array}$

'John caught a/the thief running away.'

Or 'A/the thief was running away and John caught him.'

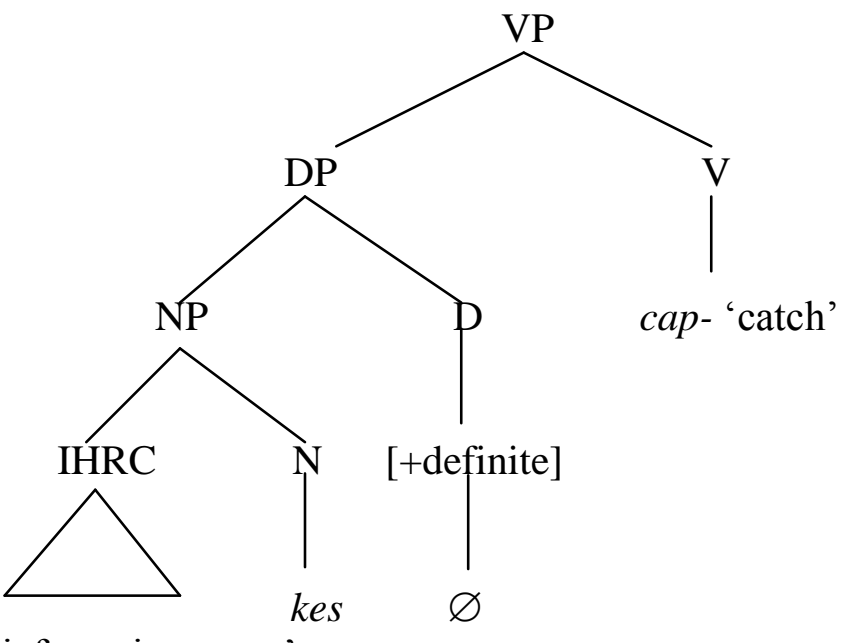

'thief running away'

Under this analysis, the DP embedding an IHRC has the semantics of an E-type pronoun: roughly speaking, it is construed as referring to a unique/maximal individual that has a salient property recovered from context. ${ }^{14}$ There are several arguments for this treatment. Of these, one notable argument is that, just like typical E-type pronouns, the kes plus [+definite] string is

\footnotetext{
${ }^{14}$ This analysis of the IHRC construction in Korean builds upon the E-type pronoun analyses of Japanese IHRCs (e.g., Hoshi 1996, Shimoyama 1999, Matsuda 2002). But it differs from them in details. Furthermore, it resolves the formal linking problem, which has afflicted its predecessors.
} 
linked to its antecedent via some sort of semantic mechanism, rather than via a syntactic mechanism like c-command. The other argument is that this string receives a unique or maximal interpretation, which is another defining property of E-type pronouns (Sells 1986, Hoshi 1995, Shimoyama 1999). To illustrate, consider (34). Here, kes is interpreted as referring to all the cookies that Mary put in the box, not just some of them. Hence the sentence is judged false if John ate only three cookies out of the five cookies that May put in the box.

\begin{tabular}{|c|c|c|c|c|}
\hline (34) John-un & [[Mary-ka & sangca-ey & kwaca-lul & tases-kay \\
\hline J.-TOP & [[M.-NOM & box-LOC & cookie-ACC & five-CL \\
\hline noh-a & twu- $\varnothing]-n$ & kes]-ul & mekessta. & \\
\hline put-COMP & auX-PST]-REL & PRON]-ACC & ate & \\
\hline
\end{tabular}

In order to derive the semantics of the IHRC construction compositionally, the following claims are made: one is that the salient property that restricts the denotation of the E-type pronoun is a thematic relation that holds between a state described by the embedded clause and an individual (e.g., Agent, Theme), as already mentioned in section 2.5. Another claim is that the relative marker - un relates the contents of the embedded clause and the embedding clause by asymmetrically coordinating them. This analysis is motivated by the well-known non-restrictive semantics of IHRCs with respect to their head noun's meaning (e.g., Jhang 1991, 1994, Jung 1995; Hoshi 1995, Shimoyama 1999), and the standard treatment of non-restrictive relatives in the literature, which utilizes a conjunction structure between the embedded and the embedding 
clauses (e.g., Déchaine 1993). Incorporating these ideas, in Kim (2007), I have offered the following lexical entries for the core components of the IHRC construction:

Lexical entry for - un: $\langle\langle\mathrm{s},\langle\mathrm{i}, \mathrm{t}\rangle\rangle,\langle\langle\mathrm{s},\langle\mathrm{i}, \mathrm{t}\rangle\rangle,\langle\mathrm{i}, \mathrm{t}\rangle\rangle\rangle$

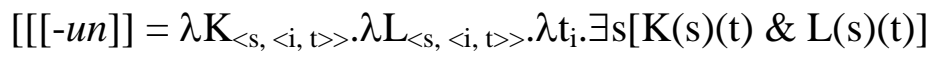

Here, $K$ and $L$ range over sets of states, $s$ over states, and $t$ over times.

(36) Lexical entry for kes: $\langle\mathrm{s},\langle\mathrm{e}, \mathrm{t}\rangle\rangle$

$\llbracket k e s \mathrm{R}, \mathrm{P} \rrbracket^{\mathrm{g}}=\lambda \mathrm{s}_{\mathrm{s}} \cdot \lambda \mathrm{x}_{\mathrm{e}}[\mathrm{g}(\mathrm{R})(\mathrm{x})(\mathrm{s}) \& \mathrm{~g}(\mathrm{P})(\mathrm{x})]$

Here, $s$ ranges over states, $x$ over individuals, $R$ over thematic relations, and $P$ over properties, and $g$ is an assignment function.

(37) Lexical entry for the definite feature: $\langle\langle\mathrm{e}, \mathrm{t}\rangle, \mathrm{e}\rangle$

$[[+$ definite $]]=\lambda \mathrm{P} . \sigma \mathrm{x}[\mathrm{P}(\mathrm{x})]$

Here, $P$ ranges over properties and ' $\sigma$ ' represents Link's (1983) sum operator.

Third, concerning the composition scheme, it was hypothesized that the IHRC undergoes LF-raising as a way to resolve its semantic type mismatch with kes. ${ }^{15}$ In brief, while an IHRC needs to combine with a function from states to sets of times, kes needs a state variable to combine with. Hence the former raises and adjoins to the appropriate level of the embedding

\footnotetext{
${ }^{15}$ LF-raising analyses of the IHRC construction have also been proposed for the Japanese IHRC construction (e.g., Fuji 1998 and Shimoyama 1999). But they differ from the analysis outlined here in their theoretical assumptions and technical executions.
} 
clause. The adjunction site is argued to be an Aspect Phrase for reasons that do not directly concern us here. What matters for our purposes is that the IHRC is interpreted higher than its surface position.

This LF-raising analysis is depicted in (38). Here, $\mathrm{K}$ and $\mathrm{J}$ respectively stand for the indices of the raised subject ${ }^{16}$ and the raised IHRC, which is labeled as RelP, shorthand for Relative Clause Phrase. Also, $t_{k}$ and $t_{j}$ stand for the traces of these moved constituents. Given the assumptions in type-driven semantics (Klein and Sag 1985), the traces get interpreted as an individual variable and a state variable, respectively.

When the LF structure gets interpreted, the indices activate the semantic operation called Predicate Abstraction (PA), given the standard assumption on semantic consequences of movement in generative grammar (e.g., Heim and Kratzer 1998). What this operation does is to create a new predicate by abstracting over a variable denoted by a trace, as indicated in the following LF structure.

\footnotetext{
${ }^{16}$ In Kim (2007), I assume the VP-internal subject hypothesis proposed by Fukui and Speas (1986), and Koopman and Sportiche (1991), among others, to keep the syntactic assumptions standard.
} 
(38) The LF structure of the IHRC construction:

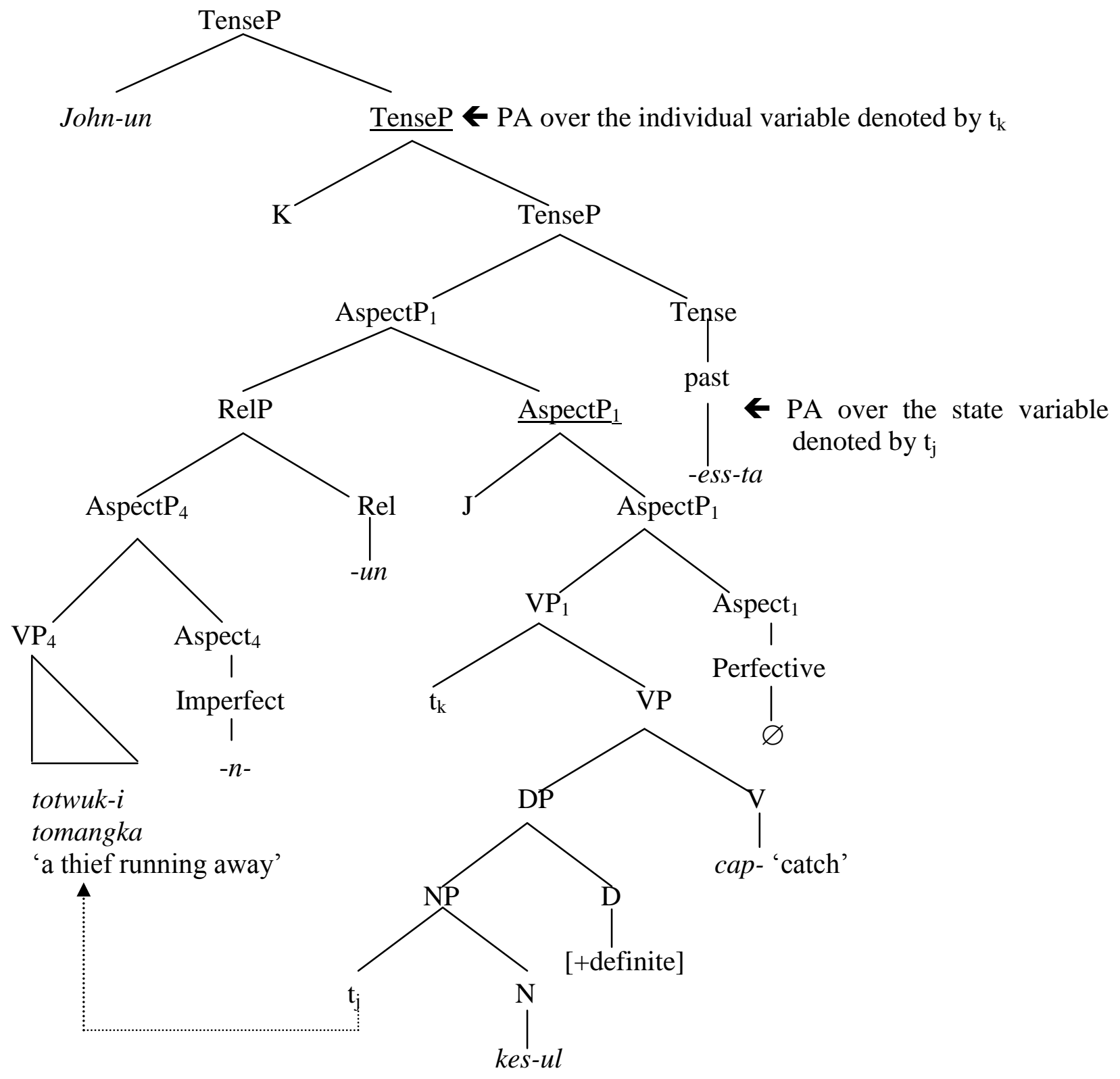

In this interpretive mechanism, the LF-raising of an IHRC has an important consequence for capturing its semantics: the trace it leaves behind gets interpreted as a state variable that combines with the denotation of kes. Crucially, this ensures that the E-type pronoun refers only 
to an individual that has a property in the eventuality denoted by the embedded clause, rather than just any prominent individual in the discourse context.

When we apply this E-type pronoun analysis of the IHRC construction to sentence (1), we obtain (39). ${ }^{17}$ Here, in-progress state means a developmental stage of a progressive event in the sense of Parsons (1990), which, by definition, contains all the event participants in its structure, and the highlighted part corresponds to the denotation of the E-type pronoun present in the embedding clause of (1).

$$
\begin{aligned}
& \text { Logical structure of (1): } \\
& \exists \mathrm{t}[\mathrm{t}<\text { now \& } \exists \mathrm{s}[\exists \mathrm{e}[\exists \mathrm{x}[\operatorname{run} . \operatorname{away}(\mathrm{e}) \& \operatorname{Agent}(\mathrm{x})(\mathrm{e}) \& \operatorname{thief}(\mathrm{x})] \& \operatorname{In}-\operatorname{progress}(\mathrm{s}, \mathrm{e}) \& \\
& \mathrm{t} \subseteq \tau(\mathrm{s})] \& \exists \mathrm{e}^{\prime}\left[\operatorname{catch}\left(\mathrm{e}^{\prime}\right) \& \operatorname{Agent}(\mathrm{John})\left(\mathrm{e}^{\prime}\right) \& \underline{\operatorname{Theme}(\sigma \mathrm{y}[\mathrm{g}(\mathrm{R})(\mathrm{y})(\mathrm{s}) \& \mathrm{~g}(\mathrm{P})(\mathrm{y})])\left(\mathrm{e}^{\prime}\right)} \&\right. \\
& \left.\left.\left.\tau\left(\mathrm{e}^{\prime}\right) \subseteq \mathrm{t}\right]\right]\right]
\end{aligned}
$$

Given the definition of an in-progress state, and given the content of the embedded clause, the assignment function $g$ yields 'Agent' as the value for $R$ and 'thief' as the value for $P$. This lets the E-type pronoun be interpreted as referring to the unique individual that bears an Agent relation to the in-progress state of the event described by the embedded clause and has the property of being a thief. Consequently, the sentence is judged to be true if a thief was running away at some time in the past and John caught the thief at that time.

What is appealing about this analysis is that the E-type pronoun present in the embedding clause has a delimited interpretive variability, since its property is supplied by the interaction between the linguistic context and the event structure of the embedded clause. Hence it can

\footnotetext{
${ }^{17}$ See Kim (2007) for the precise derivational process.
} 
capture the ambiguity of sentences like (40). Notice that (40) is three-ways ambiguous, as the English translations show.

$$
\begin{aligned}
& \text { John-un [ [koyangi-ka cwi-lul cohaka-n]-un } \quad \text { kes]-ul capassta. } \\
& \text { J.-TOP [[cat-NOM mouse-ACC chase-IMPRF]-REL PRON]-ACC caught } \\
& \text { Reading 1: 'A cat was chasing a mouse and John caught the cat.' } \\
& \text { Reading 2: 'A cat was chasing a mouse and John caught the mouse.' } \\
& \text { Reading 3: 'A cat was chasing a mouse and John caught both the cat and the mouse.' }
\end{aligned}
$$

Under the analysis advanced in Kim (2007), this sentence will receive (41) as its logical structure. Again, the highlighted part corresponds to the denotation of the E-type pronoun, i.e., the object of the matrix verb.

(41) Logical structure of (40):

$\exists \mathrm{t}[\mathrm{t}<$ now \& $\exists \mathrm{s}[\exists \mathrm{e}[\exists \mathrm{x} \exists \mathrm{y}[\operatorname{chase}(\mathrm{e}) \& \operatorname{Agent}(\mathrm{x})(\mathrm{e}) \& \operatorname{cat}(\mathrm{x}) \& \operatorname{Theme}(\mathrm{y})(\mathrm{e}) \& \operatorname{mouse}(\mathrm{y})]$ $\&$ In-progress $(\mathrm{s}, \mathrm{e}) \& \mathrm{t} \subseteq \tau(\mathrm{s})] \& \exists \mathrm{e}^{\prime}\left[\operatorname{catch}\left(\mathrm{e}^{\prime}\right) \& \operatorname{Agent}(\mathrm{John})\left(\mathrm{e}^{\prime}\right) \&\right.$ $\left.\left.\left.\underline{\operatorname{Theme}}(\sigma \mathrm{z}[\mathrm{g}(\mathrm{R})(\mathrm{z})(\mathrm{s}) \& \mathrm{~g}(\mathrm{P})(\mathrm{z})])\left(\mathrm{e}^{\prime}\right) \& \tau\left(\mathrm{e}^{\prime}\right) \subseteq \mathrm{t}\right]\right]\right]$

Since $R$ and $P$ that occur in (41) are free variables, the E-type pronoun can refer to either the cat or the mouse, because both bear a thematic relation to the state described by the embedded clause, Agent and Theme, respectively. This captures the first two possible readings of sentence (40). The third reading, namely the plural individual reading, also becomes available, because 
Link's sum operator $\sigma$ can take all the individuals that bear some thematic relation to the embedded clause's content and return a plural individual that consists of them.

To summarize the main point of Kim's (2007) analysis, the DP that directly embeds an IHRC plus kes string has the semantics of an E-type pronoun: it is interpreted as referring to a unique/maximal individual that bears a salient thematic relation to the eventuality described by the embedded clause. Importantly, this pronoun's denotation is both free and restricted. We will see below that this delimited interpretive flexibility of the IHRC+kes string gives us just what we want for the other two kes-constructions.

\subsection{Extending an E-type pronoun analysis to the other two kes-constructions}

I claim that the E-type pronoun analysis we just reviewed can be successfully extended to the perception and the factive constructions if we recast it in a Kratzerian (Kratzer 1989, 1998, 2002) situation semantics framework and make minimal amendments to its core idea. To show that this is indeed the case, I need to make a brief excursion to introduce Kratzerian situation semantic theory.

In Kratzerian situation semantics, propositions denote sets of situations in which the proposition is true, and these situations are minimal or fine-grained enough to not include anything that is irrelevant to the truth of the sentence. Another important tenet of this theory is that situations are particulars, just like individuals, and things like eventualities, states of affairs, facts, and worlds can all be subsumed under the rubric of situations. They may differ in their relative 'sizes', however: eventualities are presumably smaller than or equal to situations, and situations are in turn smaller than or equal to worlds. Thus, an eventuality, a situation, and a world can form a part-whole relation in a semi-lattice structure whose supremum is the world- 
that is, a world has a unique situation as its part, and this situation in turn has a unique eventuality as its part. ${ }^{18}$ This idea is more formally expressed by (42), which Kratzer offers in the works cited above:

(42) For all $s \in S$, there is a unique $s^{\prime} \in S$ such that $s \leq s^{\prime}$ and for all $s^{\prime \prime} \in S$, if $s^{\prime} \leq s^{\prime \prime}$, then $\mathrm{s}^{\prime \prime}=\mathrm{s}$.

This condition says that every possible situation $s$ must be related to a unique maximal element, namely, its world. Consequently, no situation can be part of more than one possible world.

Given these assumptions, under this theory, an English sentence (43) receives the logical structure given in (44).

(43) Ewan swam for ten hours.

(Kratzer 2008: ex. (59a))

(44) $\quad \lambda \mathrm{s}\left[\operatorname{past}(\mathrm{s}) \& \exists \mathrm{e}\left[\mathrm{e} \leq_{\mathrm{p}} \mathrm{s} \& \operatorname{swim}(\operatorname{Ewan})(\mathrm{e}) \& \mathrm{f}_{\text {hour }}(\mathrm{e})=10\right]\right]$

Here, $s$ ranges over situations and $e$ over eventualities, and ' $\leq_{\mathrm{p}}$ ' stands for a part-whole relation.

(Kratzer 2008: (60))

\footnotetext{
${ }^{18}$ For a comprehensive overview of Kratzerian situation semantics, in comparison with Barwise and Perry’s (1983) situation semantic theory, see Portner (1992). Kratzer (2008) also offers an overview on situation semantics in general and how it can incorporate or encompass (Neo)-Davidsonian event semantics.
} 
If we bring intensionality into the picture and also differentiate between minimal situations and maximal situations by calling the former 'situations' and the latter 'worlds', the logical form of sentence (43) will look like (45).

$$
\lambda w \exists s\left[\text { past(s) \& } \exists e\left[s \leq_{p} w \& \text { e } \leq_{p} s \& \operatorname{swim}(E w a n)(e) \& f_{\text {hour }}(e)=10\right]\right]
$$

When we transpose Kim's (2007) event-based E-type analysis of the IHRC construction into the situation semantic framework adopted here, the two core assumptions of the situation semantic theory, namely (i) the part-whole relations between different types of situations, and (ii) their status as particulars, afford us an essentially uniform analysis of the three kes-constructions at the macro-level.

First, the embedded clause of the IHRC construction now denotes (a characteristic function of) a set of situations, rather than a function from states to sets of times. Hence, we obtain (46) as the logical form of sentence (1). Notice that the only notable difference between this formula and the one in (39) is the choice of $l$ as the variable for states and $s$ as the variable for situations, a choice I have made to keep things consistent with Kratzer's example in (44).

(46) The logical structure of (1) in Kratzerian situation semantics:

$\exists \mathrm{t}\left[\mathrm{t}<\right.$ now \& $\exists \mathrm{s}\left[\exists \mathrm{l} \exists \mathrm{e}\left[\exists \mathrm{x}\left[\mathrm{e} \varsigma_{\mathrm{p}} \mathrm{s} \&\right.\right.\right.$ run.away $(\mathrm{e}) \& \operatorname{Agent}(\mathrm{x})(\mathrm{e}) \&$ thief(x)] \& In$\operatorname{progress}(1, \mathrm{e}) \& \mathrm{t} \subseteq \tau(\mathrm{l})] \& \exists \mathrm{e}^{\prime}\left[\operatorname{catch}\left(\mathrm{e}^{\prime}\right) \& \operatorname{Agent}(\mathrm{John})\left(\mathrm{e}^{\prime}\right) \& \underline{\operatorname{Theme}(\sigma \mathrm{y}[\mathrm{g}(\mathrm{R})(\mathrm{y})(\mathrm{s}) \&}\right.$ $\left.\left.\left.\mathrm{g}(\mathrm{P})(\mathrm{y})])\left(\mathrm{e}^{\prime}\right) \& \tau\left(\mathrm{e}^{\prime}\right) \subseteq \mathrm{t}\right]\right]\right]$ Here, $t$ ranges over temporal intervals, $s$ over situations, $l$ over states, $e$ over events, and $x$ and $y$ range over individuals. 
Importantly, in the adopted situation semantic framework, the embedded clauses of the perception construction and the factive construction also denote sets of situations, just as the embedded clause of the IHRC construction does, although their denotations may differ at the micro-level: the embedded clause of the IHRC construction denotes a set of eventualities (or minimal situations), the embedded clause of the perception construction denotes a set of minimal situations, and that of the factive construction denotes a set of maximal situations or worlds.

Given this situation semantic analysis of the embedded clauses of the three constructions, we can characterize the interpretive behavior of the kes string as that of an E-type pronoun across the board: in all cases, it is construed as referring to an entity that stands in a salient relation to the situation described by the embedded clause, whether this situation is an eventuality, a situation, or a world at a more fine-grained level.

Now the question is: what kind of relation does this entity bear in each case? I claim that it bears a thematic relation in the IHRC construction, a direct perceptual relation in the perception construction and a part-whole relation in the factive construction. The idea that the E-type pronoun in the IHRC construction bears a thematic relation to the content of the embedded clause is already established in Kim (2007). Hence below, I focus on the other two kesconstructions.

To begin with the perception construction, we have already seen in section 2.5 that the Etype pronoun denotes a perceptual aspect of the eventuality described by the embedded clause: e.g., it is translated as 'the scene' or 'the sound'. It is intuitively clear that things like 'scene' and 'sound' map eventualities or minimal situations onto entities that represent parts of them, in a way analogous to thematic relations such as Agent and Theme, although they are not thematic 
relations themselves. ${ }^{19}$ Hence it stands to reason that the denotation of kes that occurs in the perception construction also contains a free relation variable $R$, just like the denotation of kes in the IHRC construction does, except that this time it ranges over things like 'scene' and 'sound'. As for the free property variable $P$ that is postulated for kes's denotation in the IHRC construction, however, I suspect that we can eliminate it without any serious harm, because the object of a direct perceptual verb need not have a property like 'thief' ${ }^{20}$ I therefore propose (47) as the denotation of kes that occurs in the perception construction. Note that, here, the variables range over different things from those in (36).

(47) Lexical entry for kes in the perception construction: $\langle\mathrm{s},\langle\mathrm{e}, \mathrm{t}\rangle\rangle$ $\llbracket$ kes $\left._{\mathrm{R}}\right]^{\mathrm{g}}=\lambda \mathrm{s} . \lambda \mathrm{x}[\mathrm{g}(\mathrm{R})(\mathrm{x})(\mathrm{s})]$

Here, $g$ is an assignment function and $s$ ranges over minimal situations, $x$ over entities, and $R$ over perceptual relations.

We can give a similar treatment to the factive construction if we adopt Kratzer's (2002) notion of 'fact' and what it means to 'know that $p$ '. First, according to Kratzer, 'facts' are not synonymous with 'true propositions'; whereas propositions are sets of possible worlds, facts are particulars, each constituting just one world. Second, Kratzer proposes that for an individual $S$ to know a proposition $p$ means satisfying the following conditions:

\footnotetext{
${ }^{19}$ See Parsons (1990) and Landman (2000) for treating thematic relations as mapping between eventualities and individuals.

${ }^{20}$ I thank two anonymous reviewers for raising a question that has led to this amendment.
} 
$\mathrm{S}$ knows $\mathrm{p}$ if and only if

(i) There is a fact $f$ that exemplifies $p$,

(ii) S believes $\mathrm{p}$ de re of $\mathrm{f}$, and

(iii) $\mathrm{S}$ can rule out relevant possible alternatives of $\mathrm{f}$ that do not exemplify $\mathrm{p}$.

(Kratzer 2002: (7))

Of the three sub-conditions in (48), what is directly relevant to the present discussion are (i) and (ii). Together, they say that to know $p$ means to have the de re belief of some fact exemplifying $p$. What does it mean to have the de re belief of a fact exemplifying $p$ ? It means that the content of the belief or the re thereof matches the fact of the world in the denotation of $p$. This rules out unwanted cases in which the individual's belief about the actual world 'happens' to match some state of affairs in it. To illustrate, suppose a guy named Jones believes that the last name of the current president of South Korea is Lee. At present, the president of South Korea is Myeng-Pak Lee. Hence what Jones believes is a true proposition. But what if Jones mistakenly believes that the president's full name is Sung-Man Lee, who was the first president of the country? Under such circumstances, we cannot assert that Jones knows that the current president of South Korea's last name is Lee; his belief accidentally matches the fact, though only partly so. ${ }^{21}$ Thus, there is a need to impose the sub-condition (ii) on knowledge ascriptions.

In view of this analysis of knowledge ascriptions, the complement position of the factive construction in Korean can be said to denote the fact $f$ that exemplifies the proposition $p$ denoted by the embedded clause. Since propositions denote sets of worlds and worlds are maximal

\footnotetext{
${ }^{21}$ This illustration is adapted from Kratzer's (2002) examples (1) and (2).
} 
situations that have minimal situations, including facts, as their parts, we can restate the above statement as follows: the complement position of the factive construction refers to the fact $f$ of the world $w$ that exemplifies the proposition $p$ denoted by the embedded clause. This in turn means that, in this construction, kes relates a maximal situation or a world to its parts, namely minimal situations that we call facts. I therefore propose (49), modeling after (47).

(49) Lexical entry for kes in the factive construction: $\langle\mathrm{w},\langle\mathrm{e}, \mathrm{t}\rangle\rangle$

$\left.{ }_{[k e s}\right]^{\mathrm{g}}=\lambda \mathrm{w} \cdot \lambda \mathrm{x}[\mathrm{g}(\mathrm{R})(\mathrm{x})(\mathrm{w})]$

Here, $g$ is an assignment function and $w$ ranges over maximal situations or worlds, $x$ over entities, and $R$ over parts of worlds.

Concerning the semantics of the relativizer -un, I propose that in the perception construction, it relates two sets of minimal situations and, in the factive construction, two sets of maximal situations or worlds. This flexible semantic treatment of -un is highly plausible since its lexical entry I offered in Kim (2007) contains the logical connective ' $\&$ ', and it is well-established that logical connectives can conjoin any multiple linguistic expressions as long as they are of the same semantic type (see Partee and Rooth 1983). Thus, I posit the following lexical entries for the -un that occurs in the perception construction and the one that occurs in the factive construction by making minimal amendments to (35):

(50) Lexical entry for - un in the perception construction: $\langle\langle\mathrm{s}, \mathrm{t}\rangle,\langle\langle\mathrm{s}, \mathrm{t}\rangle, \mathrm{t}\rangle\rangle$

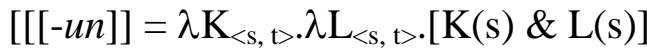

Here, $K$ and $L$ range over sets of minimal situations. 
(51) Lexical entry for - un in the factive construction: $\langle\langle\mathrm{w}, \mathrm{t}\rangle,\langle\langle\mathrm{w}, \mathrm{t}\rangle, \mathrm{t}\rangle\rangle$

$$
\left[[[-u n]]=\lambda \mathrm{K}_{<\mathrm{w}, \mathrm{t}>} . \lambda \mathrm{L}_{<\mathrm{w}, \mathrm{t}\rangle .}[\mathrm{K}(\mathrm{w}) \& \mathrm{~L}(\mathrm{w})]\right.
$$

Here, $K$ and $L$ range over sets of maximal situations or worlds.

As for the semantics of the [+definite] feature, I posit that, in the perception and factive constructions, its denotation contains the iota operator, in lieu of the sigma operator that occurs in (37). This is formally represented in (52).

$$
\begin{aligned}
& \text { Lexical entry for }[+ \text { definite }] \text { in the perception and factive constructions: }\langle<e, t\rangle, e\rangle \\
& {[[+ \text { definite }]]=\lambda P . \underline{.} x[P(x)]}
\end{aligned}
$$

Here, $P$ ranges over properties and ' $l$ ' represents the uniqueness operator.

This amendment will deliver a unique singular, rather than a maximal or plural, entity that has a salient property in the denotation of the embedded clause. The reason for this revision is that maximality may not be what is at stake in the perception and factive constructions because, for a direct perceptual report to be true, the subject need not see or hear every perceptual aspect of the relevant situation and, similarly, for a knowledge ascription to be verified, the subject need not know every fact of the relevant world. ${ }^{22}$

To summarize, I have proposed that, in all three kes-constructions, the embedded clause denotes a set of situations of some kind and the relativizer - un relates this set of situations to the set of situations of the same kind that is denoted by the embedding clause. I have also argued that,

\footnotetext{
${ }^{22}$ I thank an anonymous reviewer for raising this issue.
} 
across the board, kes relates the situation described by the embedded clause to a salient entity that bears some relation to it. In the IHRC construction, this relation is a thematic relation, as proposed in Kim (2007). In the perception construction, it spells out a perceptual aspect of a situation. In the factive construction, it amounts to a part of the world in which the embedded

clause's content is true. ${ }^{23}$ In conjunction with the proposed lexical entry for [+definite], the denotation of kes therefore lets the complement position of each construction be construed as referring to a unique thematic role bearer of the relevant eventuality, a unique visual or auditory aspect of the relevant situation, or a unique part of the relevant world. This analysis reveals that there is yet another common thread across the three constructions: at a deeper level, they all instantiate situation subordination that is facilitated by the combination of an E-type pronoun and a relativizer.

\subsection{Sample derivations}

Let me now demonstrate how the proposed analysis derives the interpretations of sentences instantiating the perception and the factive constructions. But before that, outlining the syntactic structures is in order.

Given the affinity between the complement position of the IHRC construction and that of the perception construction with respect to referential transparency, indicative mood marking, and temporal restriction discussed in sections $2.1,2.2$, and 2.3, I propose that they have an identical internal structure. Moreover, given that the complement position of the factive

\footnotetext{
${ }^{23}$ This set of statements raises the question of whether this relation can be anything other than a thematic relation, perceptual aspect of a situation, or a part relation to a world. Also, it makes us wonder whether all such relations can be subsumed as a 'part relation to a situation'. I think these are important questions on many grounds but, given their magnitude, addressing them properly will have to await another occasion.
} 
construction behaves differently in these respects, I submit that it has a different structure from the complement position of the IHRC or the perception construction. More specifically, I hypothesize that, while the embedded clause of the factive construction is a full-fledged clause or $\mathrm{CP}$ (Complementizer Phrase), the embedded clause of the other two kes-constructions consists of a small clause or TP (Tense Phrase). ${ }^{24,25}$ This would mean that a CP denotes a set of maximal situations or worlds, whereas a TP denotes a set of minimal situations. It should be stressed, however, that I am not entirely committed to calling each embedded clause a CP or a TP, since the interpretive system is presumably blind to node labels and, furthermore, any verbal projection larger than or equal to VP can denote a proposition (Portner 1992). In addition, I wish to stay neutral as to the CP vs. TP status of relative clauses in Korean. Thus I assume, as in Kim (2007), that the relativizer -un hosts its own maximal projection called RelP (Relative Clause Phrase). Furthermore, I claim that RelP is cross-categorial - that is, it can select for any type of phrase as its complement, rather than just what we call the embedded clause of the IHRC construction.

Under these assumptions, the composition scheme of the perception construction and that of the factive construction look analogous to that of the IHRC construction given above in (38); they only differ in terms of the adjunction site of the RelP at LF. ${ }^{26}$ In the case of the perception

\footnotetext{
${ }^{24}$ In the literature, a small clause analysis of the embedded clause of the direct perception construction is rather common (see Guasti 1993, Horie 1993, Felser 1998, Basilico 2003), although a similar analysis has not been put forward for the IHRC construction except for Kim (2007).

${ }^{25}$ Recall that, in Kim (2007), the embedded clause of the IHRC construction is assumed to be an Aspect Phrase. But whether it is indeed an Aspect Phrase or not will not have direct bearing on the analysis advanced here.

${ }^{26}$ An anonymous reviewer wonders whether the proposed LF-raising of the RelP violates the island constraint, since it involves raising out of a DP. In this structure, however, the RelP is the complement to kes and raising out of
} 
construction, the RelP adjoins to the TP of the embedding clause, as illustrated in (53) for sentence (29). This LF-raising is again invoked to resolve a semantic type mismatch between the RelP and kes: the RelP denotes a function from a set of situations to a function from a set of situations to truth-values and kes denotes a function from situations to entities. Hence they cannot combine with each other. ${ }^{27}$ By undergoing LF-raising to the embedding clause's TP level, the RelP meets the right argument, namely, a situation-level denotation of the embedding clause and it also supplies the right argument for kes, because its trace gets interpreted as a situation variable that gets bound by the lambda abstractor that is introduced by its index $\mathrm{J}$, given the assumptions of type theory (Klein and Sag 1985).

complements is usually allowed even in English, as illustrated in (i), even though rather rigid island constraints seem to apply to English.

(i) John, whose fiancé is a medical doctor, came to our party.

Furthermore, Korean does not seem to comply with the same kind of island constraints as English does. This is exemplified by the following sentence, in which the nominal shinsa 'gentleman' (or the relative operator, depending on one's theory of the syntax of relative clauses) has raised crossing two bounding nodes, namely RelP and $_{1} \mathrm{DP}_{1}$.

(ii) $\left[\mathrm{DP} 2\left[\right.\right.$ RelP2 $\left[\mathrm{DP1}\left[\mathrm{RelP1} e_{\mathrm{i}} \quad\right.\right.$ ip-ko $\quad$ iss-n]-un $\quad$ os $]-\mathrm{i} \quad$ mesiss-n]-un $\quad s h i n s a_{i}$ [ [ [ [ wear-CONN be-IMPRF]-REL clothes]-NOM be.nice-IMPRF]-REL gentleman Lit.: The gentleman such that the clothes that he is wearing are nice.

Given these facts, I believe that the LF-raising analysis adopted here does not necessarily conflict with the usual assumptions about constraints on movement in Korean (and also in other languages).

${ }^{27}$ There might be alternative ways to resolve this type mismatch, employing a type-shifting mechanism being one of them. But I will have to defer exploring such alternative avenues to another occasion. 
John-un [[totwuk-i tomangka-n]-un kes]-lul tul-ess-ta.

J.-TOP [[thief-NOM run.away-IMPRF]-REL PRON]-ACC hear- PST-DECL

'A/the thief was running away and John heard it (= the sound).'

The LF structure of (29): ${ }^{28}$

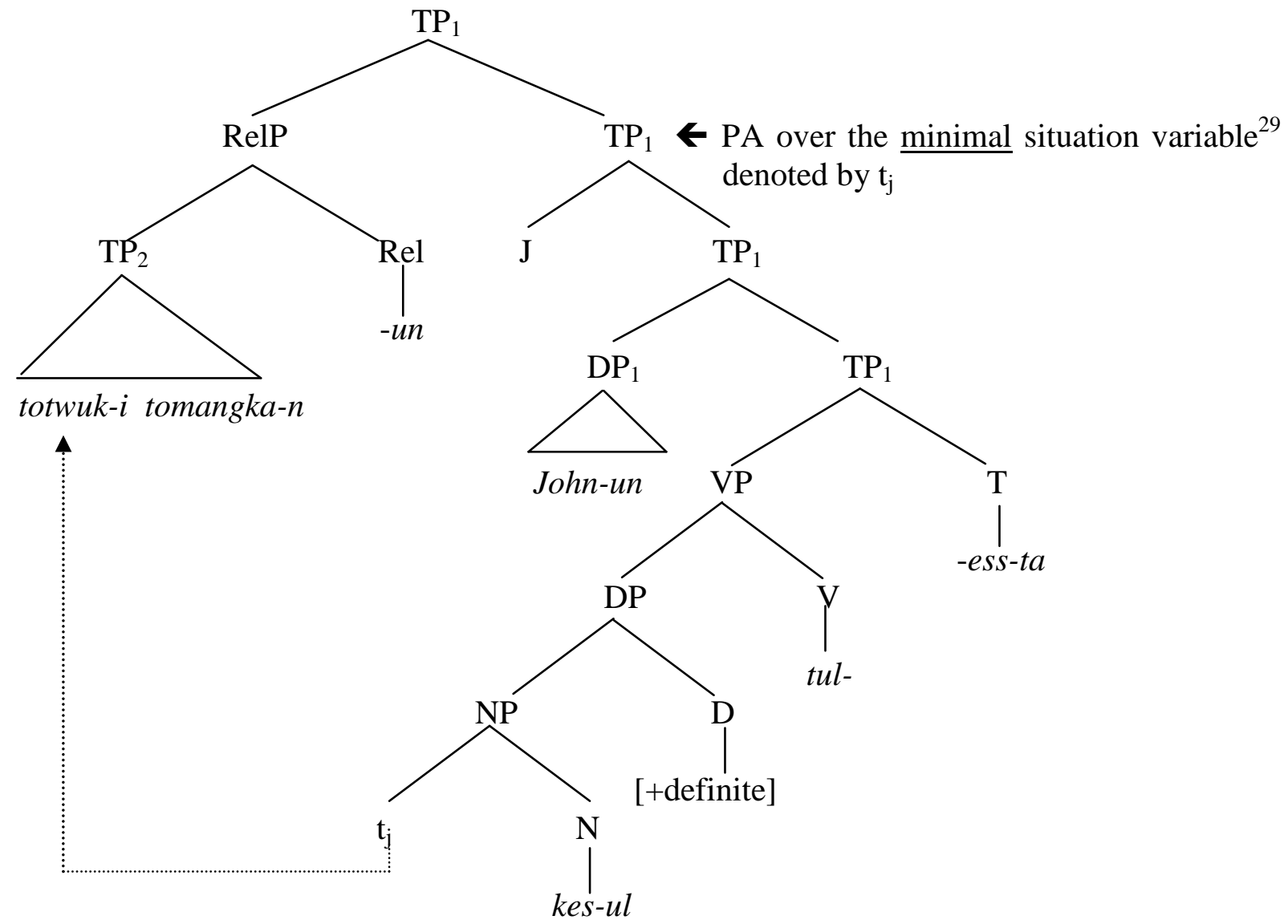

${ }^{28}$ For expositional simplicity, here and below, I do not assume the VP-internal subject hypothesis as in Kim (2007). But this simplification has no impact on the main argumentation of the present analysis.

${ }^{29}$ When (38) is transposed into the current semantic framework, the PA operation that occurs over a state individual there will be over a minimal situation variable, as it is here. 
When we interpret this LF by plugging in the proposed lexical entries for the core components of the perception construction while making the standard assumption about past tense as a relation between topic time and speech time (Klein 1994), we obtain (54) as the logical form for (29). ${ }^{30}$

$$
\begin{aligned}
& \text { Logical form of (29): } \\
& \exists \mathrm{t}\left[\mathrm{t}<\operatorname{now} \& \exists \mathrm{s}\left[\exists \mathrm { l } \exists \mathrm { e } \left[\exists \mathrm{x}\left[\mathrm{e} \leq_{\mathrm{p}} \mathrm{s} \& \text { run.away(e) \& } \operatorname{Agent}(\mathrm{x})(\mathrm{e}) \& \operatorname{thief}(\mathrm{x})\right] \&\right.\right. \text { In- }\right. \\
& \operatorname{progress}(1, \mathrm{e}) \& \mathrm{t} \subseteq \tau(\mathrm{l})] \& \mathrm{e}^{\prime}\left[\operatorname{hear}\left(\mathrm{e}^{\prime}\right) \& \operatorname{Agent}(\mathrm{John})\left(\mathrm{e}^{\prime}\right) \& \underline{\operatorname{Theme}(\mathrm{ly}[\mathrm{g}(\mathrm{R})(\mathrm{y})(\mathrm{s})])\left(\mathrm{e}^{\prime}\right)}\right. \\
& \left.\left.\left.\& \tau\left(\mathrm{e}^{\prime}\right) \subseteq \mathrm{t}\right]\right]\right]
\end{aligned}
$$

This logical form is nearly identical to (46) except for the highlighted part. But the interpretation it receives is slightly different: given the lexical semantics of the embedding predicate 'hear', we supply an audio perceptual relation as the value for $R$. Hence, the sentence is construed as meaning that John heard the unique sound of the situation that contains the event of the thief running away.

In the case of the factive construction, I hypothesize that the RelP raises at LF and adjoins to the $\mathrm{CP}$ of the embedding clause, as illustrated in (55) for sentence (3). The landing site is higher than in the perception construction because the RelP embeds a $\mathrm{CP}$ and thus it is looking for another CP-level denotation to combine with, given the lexical entry for the morpheme -un proposed in (51) and the assumption that a CP denotes a set of maximal situations or worlds.

\footnotetext{
${ }^{30} \mathrm{I}$ abstract away from how exactly the embedded and the embedding clauses end up being evaluated with respect to the same topic time, because doing justice to this question will inevitably involve touching on the sequence of tense phenomenon, which is a complex topic in and of itself and thus will go well beyond the scope of this paper.
} 
(3)

$\begin{array}{lllll}\text { John-un } & {[[\text { totwuk-i }} & \text { tomangka-n]-un } & \text { kes }]-u l & \text { al-ass-ta. } \\ \text { J.-TOP } & {[[\text { thief-NOM }} & \text { run.away-IMPRF]-REL } & \text { PRON]-ACC } & \text { know-PST-DECL }\end{array}$

'A/the thief was running away and John knew the fact.'

(55) The LF structure of (3):

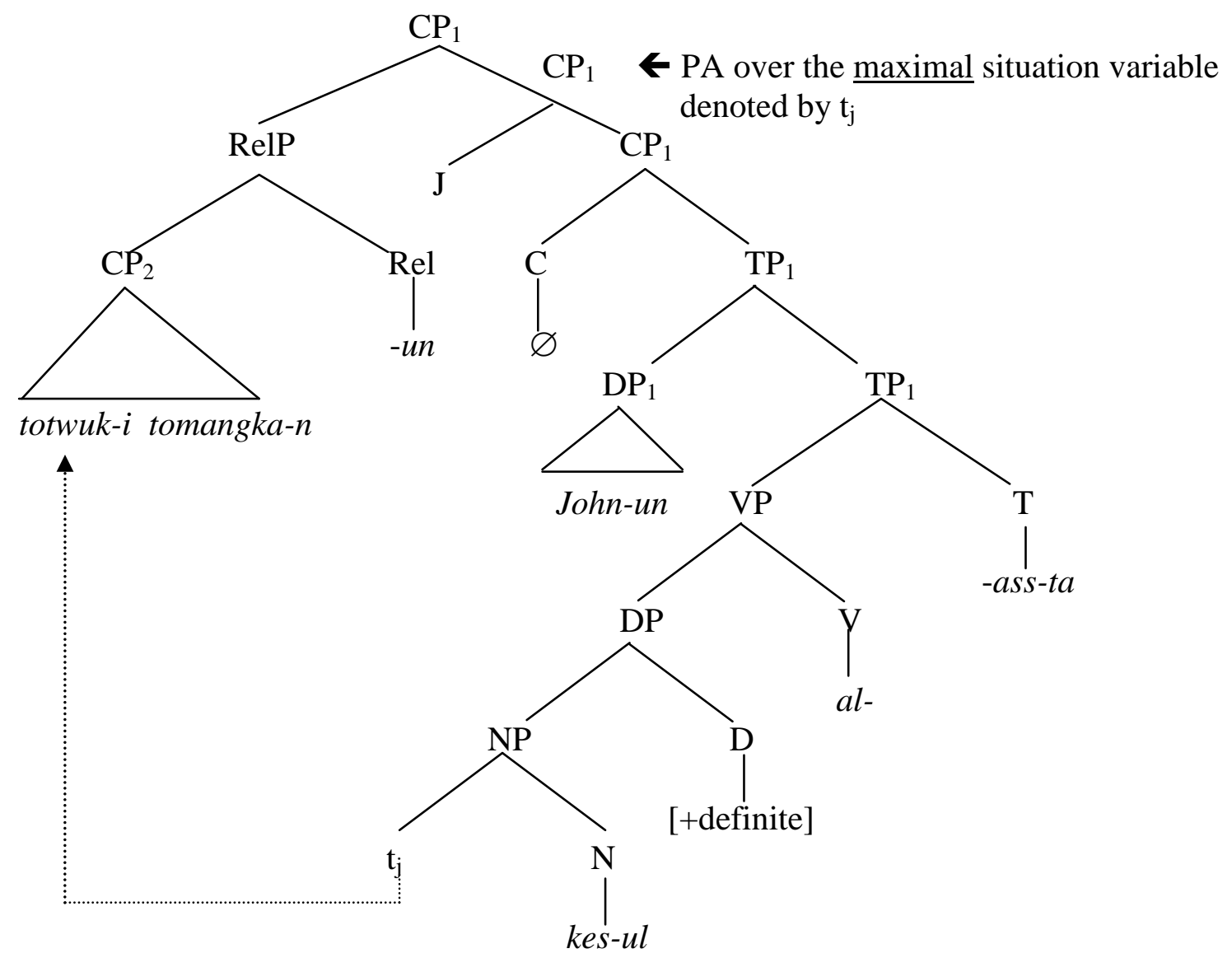

When we compute the above LF, we obtain (56). 
$\lambda \mathrm{w} . \exists \mathrm{t}\left[\mathrm{t}<\right.$ now $\& \exists \mathrm{s}\left[\exists \mathrm{l} \exists \mathrm{e}\left[\exists \mathrm{x}\left[\mathrm{s} \leq_{\mathrm{p}} \mathrm{w} \& \mathrm{e} \leq_{\mathrm{p}} \mathrm{s} \& \operatorname{run} . \operatorname{away}(\mathrm{e}) \& \operatorname{Agent}(\mathrm{x})(\mathrm{e}) \& \operatorname{thief}(\mathrm{x})\right] \&\right.\right.$ $\operatorname{In}-\operatorname{progress}(1, \mathrm{e}) \& \mathrm{t} \subseteq \tau(1)] \& \lambda \mathrm{w}^{\prime} \exists \mathrm{s}^{\prime} \exists \mathrm{e}^{\prime}\left[\mathrm{s}^{\prime} \leq_{\mathrm{p}} \mathrm{w}^{\prime} \& \mathrm{e}^{\prime} \leq_{\mathrm{p}} \mathrm{s}^{\prime} \& \operatorname{know}\left(\mathrm{e}^{\prime}\right) \& \operatorname{Agent}(\operatorname{John})\left(\mathrm{e}^{\prime}\right)\right.$ $\left.\left.\left.\& \underline{\text { Theme }(\sigma y[g(R)(y)(w)])\left(e^{\prime}\right)} \& \tau\left(e^{\prime}\right) \subseteq \mathrm{t}\right]\right]\right]$

Again, the highlighted part corresponds to the interpretation of the complement position. Given the content of the embedded clause, $R$ is interpreted as 'part'. So the E-type pronoun present in the embedding clause gets construed as referring to a unique entity that stands in a part relation to the world described by the embedded clause. This makes the sentence judged to be true if and only if John knew the unique situation or fact of the world that verifies the proposition that a thief was running away at that time, ${ }^{31}$ provided that all the three conditions on knowledge ascription given in (48) are also met - that is, (i) there is indeed a fact of a thief running away in the actual world, (ii) John has a de re belief of the fact, and (iii) he can also rule out relevant possible alternatives of the fact that do not exemplify the proposition.

\footnotetext{
${ }^{31}$ On the present analysis, the propositional attitude verb al- 'to know' is a two-place relation between two individuals, rather than a characteristic function from a set of worlds to an individual, as standardly assumed. This makes the relation between the embedded clause's content and the attitude holder, i.e., the subject of the embedding clause, not so direct; they are related indirectly via an E-type pronoun that bears a relation to the embedded clause's content. To the extent that this analysis correctly captures native speakers' intuitions about various sentences instantiating the factive construction, we can conclude that there is a way to capture the semantics of knowledge ascriptions without adopting the standard analysis of attitude predicates.
} 


\subsection{Back to the properties of kes-constructions}

Let me now revisit the properties of the three kes-constructions presented in section 2 and show how the proposed analysis sheds new light on them.

First of all, in the light of this analysis, the three constructions have a seemingly identical surface form, because their core components have similar lexical entries, leading them to have similar composition schemes. More specifically, in each case, (i) the embedded clause describes a situation of some kind; (ii) the relativizer - un relates two sets of situations denoted by the embedded and the embedding clauses by LF-raising to the relevant projection of the embedding clause; (iii) the pronominal kes relates the minimal or maximal situation described by the embedded clause to some entity that bears a relation to it; fially, (iv) the [+definite] feature makes this entity unique, be it singular or plural.

The present analysis also accounts for why kes behaves like a disguised definite expression, receiving the interpretation of 'the $\mathrm{X}$ ', as shown in section 2.5. It is because kes is in fact the phonological representation of the E-type pronoun that is present in the embedding clause, whose interpretation is built from combining the trace of the raised RelP, the pronominal kes itself, and the [+definite] feature. Kes can have a flexible semantics that accommodates all the three constructions because, in the Kratzerian situation theory adopted here, situations are particulars and thus can stand in a relation to another particular or entity.

Treating the kes string as an E-type pronoun also offers a relatively simple account of the presuppositionality of the three constructions discussed in section 2.4. Since E-type pronouns can be analyzed as disguised definite descriptions (Elbourne 2005), it is reasonable to assume that the denotation of the kes string comes with a built-in existential presupposition that its descriptive content is non-null. This makes a sentence instantiating one of the three kes- 
constructions judged felicitous only if the situation described by the embedded clause exists in the world of evaluation; otherwise, it will be undefined. We can also attribute the presuppositional behavior of three kes-constructions to the semantics of -un. This morpheme's denotation contains the logical connective ' $\&$ ' and this makes the logical structures of all the three constructions have the form of $p \& q$. Since $p$ and $q$ correspond to the embedded clause's content and the embedding clause's content, respectively, the truth of a sentence instantiating a kes-construction is bound to entail the truth of the embedded clause. Consequently, the situation it describes has to exist in some world.

Why is it then that the three constructions exhibit different kind of existential presuppositionality, namely, true factivity vs. potential factivity (or simple existential presuppositionality)? The factive construction displays true factivity because it is concerned with connecting two sets of maximal situations or worlds, which in turn make up two assertions about the actual world, one assertion expressed by the embedded clause and the other expressed by the embedding clause. Hence a sentence instantiating the construction cannot be judged true unless the embedded clause's content denotes a true proposition, i.e., a set of situations that we call facts. In the case of the IHRC and the perception constructions, they merely display potential factivity because they are concerned with connecting two minimal situations, ${ }^{32}$ which together form just one maximal situation or world. Hence, if their embedded clauses contain imperfective

\footnotetext{
${ }^{32}$ It has been claimed by several authors that the semantics of the IHRC construction has to do with connecting two eventuality descriptions although the claim was not made in the exact same terms (e.g., Kuroda 1992, Ohara 1993, Kim 2002, Matsuda 2002, Chung and Kim 2003). Similarly, the perception constructions in English and German have been argued to describe a (part-whole) relation between eventualities (e.g., 1983, Felser 1999, Basilico 2003). Since we treat eventualities as a type of situations here, we can say that the existing body of literature lends independent support to the present analysis of the IHRC and the perception constructions.
} 
aspect and are under intensional operators, as in (22) and (26), then they do not necessarily describe a fact; rather, they describe a situation that is expected to exist in some possible world by some relevant individual. For instance, in (22), the situation of Mary running in the race was presupposed to be actualized by John. But, given the semantics of imperfective, which is akin to that of progressive (see Dowty 1979, Portner 1992, and Landman 1992), such an actualization is not guaranteed and hence the presupposition can be canceled.

We can apply a similar logic to explaining why the IHRC and the perception constructions behave differently from the factive construction with regard to the referential transparency, indicative mood marking, and predicate restriction that pertains to the embedded clause, as shown in sections 2.1, 2.2, and 2.3, respectively.

First, the embedded clauses of the IHRC and the perception constructions are referentially transparent because they denote sets of minimal situations and hence they have to be evaluated relative to the same world as the one in the embedding clause's denotation. The embedded clause of the factive construction can be referentially opaque, on the other hand, because its denotation contains a world variable of its own, independently from the embedding clause.

Second, indicative mood marking is not possible in the embedded clause of the IHRC or the perception construction but possible in the embedded clause of the factive construction because the former two denote minimal situations and thus are incompatible with indicative mood marking, which is presumably only allowed in assertions.

Third, the embedded clauses of the IHRC and the perception construction cannot tolerate Ilevel predicates because, in order for situation subordination to work, the situations involved have to be of the same kind: in these constructions, the embedding clauses describe spatiotemporally bound situations, due to the lexical semantics of their predicates, such as 'catch' and 
'see'. Thus, if the embedded clause describes a semi-permanent situation, as in (14) and (15), then it cannot 'connect well' with the embedding clause's content. ${ }^{33}$ Support for this analysis comes from the fact that when the embedding predicate is changed to an I-level predicate, the predicate restriction on the embedded clause disappears except that such cases will no longer be considered instances of the IHRC construction. To illustrate, compare (14a) and (57). The former is repeated from above.

(14) a. *John-un [Mary-ka changnankkwuleki-i- $\varnothing]$-un kes-ul mak-ass-ta. J.-TOP [M.- NOM goofy.person-COP-N.PST]-REL PRON]-ACC stop-N.PST-DECL Intended: 'John stopped Mary, who is a goofy person.'

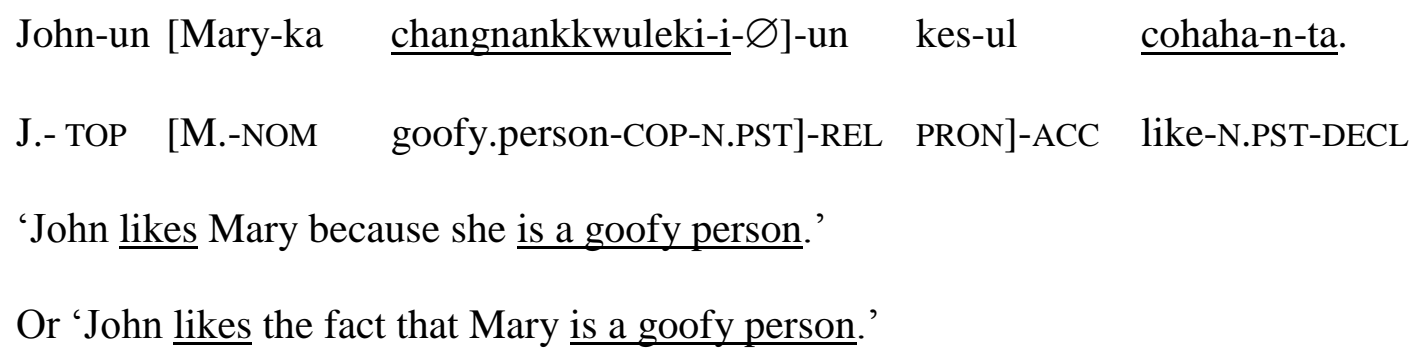

On the account I just outlined, the grammaticality of (57) is expected because here, both the embedded clause and the embedding clause have the same type of predicate and thus they describe the same type of situations, namely, semi-permanent situations. (14a) is ungrammatical,

\footnotetext{
${ }^{33}$ A similar account was offered by Kim (2002) for the predicate restriction on the IHRC construction. But his analysis resorts to the impossibility of establishing binding relation between the event arguments in the denotations of the embedded and the embedding clauses, when an I-level predicate occurs in the embedded clause.
} 
by contrast, because the embedded clause describes a semi-permanent situation whereas the embedding clause describes a temporary situation.

\subsection{Application to other kes-constructions}

Since sentence (57) is another instance of kes-construction although it apparently defies any of the three labels we have been using in this paper, one may wonder how the proposed analysis may derive the semantics of other kes-constructions that have been set aside for the reasons given in footnote 3. The simple answer is that other kes-constructions can receive an essentially identical semantic treatment to the three kes-constructions examined above, in spite of their subtle syntactic and semantic differences. To illustrate, sentence (57) receives the following interpretation:

$$
\text { The logical structure of (57): }
$$

$\lambda \mathrm{w} . \exists \mathrm{t}\left[\mathrm{t}<\right.$ now $\& \exists \mathrm{s}\left[\exists 1\left[\exists \mathrm{x}\left[\mathrm{s} \leq_{\mathrm{p}} \mathrm{w} \& 1 \leq_{\mathrm{p}} \mathrm{s} \&\right.\right.\right.$ goofy_person(l) \& Theme $\left.\left.(\mathrm{x})(1) \& \mathrm{t} \subseteq \tau(1)\right)\right]$

$$
\text { \& } \quad \lambda \mathrm{w}^{\prime} \exists \mathrm{s}^{\prime} \exists \mathrm{e}^{\prime}\left[\mathrm{s}^{\prime} \quad \leq_{\mathrm{p}} \quad \mathrm{w}^{\prime} \quad \& \quad \mathrm{e}^{\prime} \quad \leq_{\mathrm{p}} \quad \mathrm{s}^{\prime} \quad \& \quad \text { like(e') \& } \quad \text { Agent(John)(e') } \quad\right. \text { \& }
$$
$\left.\left.\left.\underline{\text { Theme }(\sigma y[g(R)(y)(w)])\left(e^{\prime}\right)} \& \tau\left(e^{\prime}\right) \subseteq \mathrm{t}\right]\right]\right]$

This logical form suggests that the embedded clause of (57) is a full-fledged clause or CP which denotes a set of worlds. There is in fact supporting evidence for such a treatment: the embedded clause of this sentence can contain the indicative mood marker $-l a$, a morphophonemic variant of $-t a,{ }^{34}$ just like the embedded clause of the factive construction can, as we saw in section 2.4. To see this, consider (59), in comparison with (57).

\footnotetext{
${ }^{34}$ The morpheme - $t a$ becomes - $l a$ when immediately following copula.
} 


$$
\begin{aligned}
& \text { John-un [Mary-ka changnankkwuleki-i- } \varnothing \text {-la]-un kes-ul cohaha-n-ta. } \\
& \text { J.-TOP [M.-NOM goofy.person-COP-N.PST-IND]-REL PRON]-ACC like-N.PST-DECL } \\
& \text { 'John likes the fact that Mary is a goofy person.' }
\end{aligned}
$$

Under the present analysis, we can in fact also capture the ambiguity of (57): that is, what John likes is either Mary or the fact that she is a goofy person. The logical form given in (58) allows for either reading, because both Mary and the fact that she is goofy person are part of the world described by the embedded clause, so the free variable $R$ inside the denotation of kes can map the world onto either of them. ${ }^{35}$

Given this welcome result and the preceding discussion, I conclude that the proposed analysis can not only account for all the challenging properties of the three kes-constructions identified in this article but also capture other kes-constructions as well.

\section{Summary and Conclusion}

The overarching goal of this article was to account for why the IHRC, the direct perception, and the factive constructions in Korean have a prima facie identical form, despite their finegrained semantic differences. Along the way, I have also clarified how exactly the three constructions are similar and dissimilar to each other. We have seen that there is more parallel between the IHRC and the perception construction than between the perception and the factive construction, contra the prevailing view. Yet we have also seen that, at a more macro-level, the

\footnotetext{
${ }^{35}$ A virtually identical analysis can be given of sentence (i) in footnote 3.
} 
three constructions are more alike than different: they all exhibit presuppositionality with respect to their complement positions and also instantiate E-type anaphora.

I have proposed a globally uniform but locally individualized account of the three constructions by recasting Kim's (2007) event-based E-type pronoun analysis of the IHRC construction within a Kratzerian situation semantics framework. The core idea was that the three kes-constructions parallel each other because they all instantiate situation subordination wherein an E-type anaphor and a relativizater mediate between the subordinate and the superordinate clauses.

The proposed analysis implicates that a relativizer and an E-type pronoun have a greater semantic versatility than standardly assumed: a relativizer is canonically believed to connect two sets of individuals, as is the case in the externally headed relative clause construction. But it can connect two sets of situations as well, as we saw here. An E-type pronoun is usually believed to denote a unique or maximal entity with a salient property such as 'being a thief'. Obviously, however, it can also refer to a unique entity that bears a salient relation to a situation such as 'a perceptual aspect of a minimal situation'.

This semantic versatility of E-type pronouns and relativizers lets us see how employing a pronoun can maximize functional efficiency in creating a complex clause construction, be it a relative clause or a complement clause construction. It therefore provides a possible account of why clausal modifiers and complements seem to bear the same form across languages: e.g., in many languages, complementizers tend to have the same morphology as $3^{\text {rd }}$ person singular pronouns, just like that in English or kes in Korean. The reason is that such pronouns can have the semantics of an E-type pronoun which relates a situation to a salient entity in it. It remains to be seen how the factual generalizations about the three kes-constructions in Korean and the 
proposed semantic analyses thereof can carry over to the corresponding constructions in other languages, such as Japanese and Quechua. ${ }^{36}$

\section{Acknowledgements}

Parts of this work were presented at the $10^{\text {th }}$ Harvard International Symposium on Korean Linguistics and the $13^{\text {th }}$ Japanese/Korean Linguistics Conference. I thank the audiences for tolerating many of the holes in the analyses and still being encouraging. Special thanks go to Christopher Potts, Peter Sells, Hee-Rak Chae, Yukinori Takubo, Shigeru Miyagawa, and Elena Rudnitskaya for reading a draft of this article at some point and offering invaluable comments on it. I also benefited immensely from the insightful comments and constructive criticisms from three anonymous reviewers of NLLT. Last but not least, I am indebted to Marcel den Dikken, the Editor-in-Chief of the journal, for the excellent editorial support throughout the publication process. Needless to say, I am solely responsible for all remaining errors and inadequacies.

\section{References}

Basilico, David. 2003. The topic of small clauses. Linguistic Inquiry 34: 1-35. Barwise, Jon. 1981. Scenes and other situations. Journal of Philosophy 78: 369-197. Barwise, Jon \& John Perry. 1983. Situations and Attitudes. Cambridge, MA: MIT press.

\footnotetext{
${ }^{36}$ As mentioned in footnote 2, in Japanese, in the IHRC and the direct perception constructions, no occurs in the position where kes would occur in Korean but, in the factive construction, koto occurs instead. This fact accords well with the generalization offered here, namely that the IHRC and the perception constructions form one subclass and the factive construction forms another. One might wonder whether the fact that Japanese makes a morphological distinction between these two subclasses would pose a challenge to the analysis put forward here. I believe that it does not: the proposed E-type pronoun analysis can actually accommodate koto-constructions rather easily by assigning an appropriate lexical entry to it, such as what is posited for kes in (49).
} 
Berg, Jonathan. 1988. The pragmatics of substitutivity. Linguistics and Philosophy 11(3): 355370.

Chae, Hyon Sook. 2007. On the categorial ambiguity of the morpheme kes in Korean. Language Research 43(2): 229-264.

Chomsky, Noam. 1977. Essays on Form and Interpretation. Elsevier North-Holland, Inc.

Chung, Chan and Jong-Bok Kim. 2003. Differences between externally and internally headed relative clause constructions. In On-line Proceedings of HPSG 2002, ed., J.-B. Kim, 3-25.

Chung, Dae-ho. 1999. A complement analysis of the head internal relative clauses. Language and Information 3: 1-12.

Déchaine, Rose-Marie. 1993. Predicates Across Categories. Ph.D. Dissertation, University of Massachusetts-Amherst.

Dowty, David. 1979. Word Meaning and Montague Grammar. Ph.D. Dissertation, University of Texas.

Elbourne, Paul. 2005. Situations and Individuals. Cambridge, MA: MIT Press.

Felser, Claudia. 1999. Verbal Complement clauses: A Minimalist Study of Direct Perception Constructions. Philadelphia: John Benjamins.

Fuji, Masaaki. 1998. Temporal interpretation of internally headed relative clauses in Japanese. Working Papers from Rutgers University 1: 75-91.

Fukui, Naoki and Margaret Speas. 1986. Specifiers and projection. MIT working papers in linguistics 8:128-172.

Guasti, Maria-Teresa. 1993. Causative and Perception Verbs: A Comparative Study. Torino: Rosenberg \& Sellier.

Heim, Irene. 1992. Presupposition projection and the semantics of attitude verbs. Journal of Semantics 9: 183-221.

Heim, Irene and Angelika Kratzer. 1998. Semantics in Generative Grammar. Oxford: Blackwell.

Higginbotham, J. 1983. The logic of perceptual reports: an extensional alternative to situation semantics. The Journal of Philosophy 80:100-127.

Horie, Kaoru. 1993. A cross-linguistic study of perception and cognition verb complements: a cognitive perspective, Ph.D. Dissertation, University of Southern California.

Hoshi, Koji. 1995. Structural and interpretive aspects of head-internal and head-external relative 
clauses, Ph.D. Dissertation, University of Rochester.

Jhang, Sea-eun. 1991. Internally headed relative clauses in Korean. In Harvard Studies in

Korean Linguistics, eds. S. Kuno et al., 269-280. Seoul, Korea: Hanshin Publishing.

Jhang, Sea-eun. 1994. Headed nominalizations in Korean: relative clauses, clefts, and comparatives, Ph.D. Dissertation, Simon Fraser University.

Jo, Mi-Jeung. 2003. The correlation between syntactic nominalization and the internally headed relative constructions in Korean. Studies in Generative Grammar 13:535-564.

Jung, Yunsun. 1995. Internally headed relative clauses in Korean. In Harvard Studies in Korean Linguistics, eds. Kuno et al., 235-248. Seoul, Korea: Hanshin.

Karttunen, Lauri. 1973. Presuppositions of compound sentences, Linguistic Inquiry 4: 169-193.

Kim, Min-Joo. 2004. Event Structure and the Internally-Headed Relative Clause Construction in Korean and Japanese. Ph.D. Dissertation, University of MassachusettsAmherst.

Kim, Min-Joo. 2007. Formal linking in internally headed relatives. Natural Language Semantics 15: 279-315.

Kim, Nam-Kil. 1984. The Grammar of Korean Complementation. University of Hawaii at Manoa: Center for Korean Studies.

Kim, Yong-Beom. 2002. Relevancy in internally headed relative clauses in Korean. Lingua 112:541-559.

Kiparsky, Paul and Carol Kiparsky. 1970. Fact. In Progress in Linguistics, eds. Manfred.

Bierwisch and Karl Erich Heidolph, 143-73. The Hague: Mouton.

Klein, Ewan and Ivan Sag. 1985. Type-driven translation. Linguistics and Philosophy 8:163-201.

Klein, Wolfgang. 1994. Time in Language. London: Routledge.

Koopman, Hilda and Dominique Sportiche. 1991. The position of subjects. Lingua 85:211-258.

Kratzer, Angelika. 1989. An Investigation of the Lumps of Thought. Linguistics and Philosophy 12: $607-653$.

Kratzer, Angelika. 1998. Scope or pseudoscope? Are there wide-scope indefinites? In Events and Grammar, ed. Susan Rothstein, 163-196. Dordrecht: Kluwer Academic Publishers.

Kratzer, Angelika. 2002. Facts: Particulars or information units? Linguistics and Philosophy 25 (2): 655-670.

Kratzer, Angelika. 2008. Situations in Natural Language Semantics, Stanford Encyclopedia of 
Philosophy, http://plato.stanford.edu/entries/situations-smantics/\#SitSemDavEveSem.

Kuno, Susumu. 1973. The structure of the Japanese language. Cambridge, MA: Massachusetts Institute of Technology.

Kuroda, Shige-yuki. 1992. Japanese Syntax and Semantics. Dortrecht: Kluwer Academic Publishers.

Landman, Fred. 1992. The progressive. Natural Language Semantics 1: 1-32.

Landman, Fred. 2000. Events and Plurality: The Jerusalem Lectures. Dortrecht: Kluwer.

Lee, Miae. 2004. Focus-induced constraints in head-internal relatives. In Harvard Studies in Korean Linguistics, eds. S. Kuno et al., 568-581.

Lee, Jeong-Rae. 2006, The Korean Internally Headed Relative Clause Construction: Its Morphological, Syntactic and Semantic Aspects, Dissertation, University of Arizona.

Lefebvre, Claire and Pieter Muysken. 1988. Mixed categories, nominalizations in Quechua. Boston, MA: Kluwer.

Matsuda, Yuki. 2002. Event sensitivity of head-internal relatives in Japanese. Japanese/Korean Linguistics 10: 629-643.

Ohara, H. K. 1993. On Japanese internally headed relative clauses. Proceedings of BLS 18, Buszard-Wechsler et al. eds., 100-109.

Parsons, Terence. 1990, Events in the Semantics of English: A Study in Subatomic Semantics. Cambridge, MA: MIT Press.

Partee, Barbara H. and Mats Rooth. 1983. Generalized conjunction and type ambiguity. In Meaning, Use, and Interpretation of Language, eds. Rainer Bäuerle, Christoph Schwarze and Arnim von Stechow, 361-383. Berlin: de Gruyter.

Portner, Paul. 1992. Situation Theory and the Semantics of Propositional Expressions. Ph. D. dissertation, University of Massachusetts at Amherst.

Sells, Peter. 1986. Coreference and bound anaphora: a restatement of the facts. In Proceedings of NELS 16, eds. J.-W. Choe S. Berman, and J. McDonough. University of MassachusettsAmherst: the GLSA publications.

Shimoyama, Junko. 1999. Internally headed relative clauses in Japanese and E-type anaphora. Journal of East Asian Linguistics 8:147-182. 